\title{
Genipin Cross-Linked Polymeric Alginate-Chitosan Microcapsules for Oral Delivery: In-Vitro Analysis
}

\author{
Hongmei Chen, Wei Ouyang, Christopher Martoni, and Satya Prakash \\ Biomedical Technology and Cell Therapy Research Laboratory, Department of Biomedical Engineering and Physiology, \\ Artificial Cells and Organs Research Centre, Faculty of Medicine, McGill University, Montreal, QC, Canada H3A 2B4
}

Correspondence should be addressed to Satya Prakash, satya.prakash@mcgill.ca

Received 24 September 2008; Revised 9 March 2009; Accepted 29 April 2009

Recommended by Miriam Rafailovich

\begin{abstract}
We have previously reported the preparation of the genipin cross-linked alginate-chitosan (GCAC) microcapsules composed of an alginate core with a genipin cross-linked chitosan membrane. This paper is the further investigation on their structural and physical characteristics. Results showed that the GCAC microcapsules had a smooth and dense surface and a networked interior. Cross-linking by genipin substantially reduced swelling and physical disintegration of microcapsules induced by nongelling ions and calcium sequestrants. Strong resistance to mechanical shear forces and enzymatic degradation was observed. Furthermore, the GCAC membranes were permeable to bovine serum albumin and maintained a molecular weight cutoff at $70 \mathrm{KD}$, analogous to the widely studied alginate-chitosan, and alginate-poly-L-lysine-alginate microcapsules. The release features and the tolerance of the GCAC microcapsules in the stimulated gastrointestinal environment were also investigated. This GCAC microcapsule formulation offers significant potential as a delivery vehicle for many biomedical applications.
\end{abstract}

Copyright (C) 2009 Hongmei Chen et al. This is an open access article distributed under the Creative Commons Attribution License, which permits unrestricted use, distribution, and reproduction in any medium, provided the original work is properly cited.

\section{Introduction}

Bioencapsulation describes a procedure where biologically active materials are enclosed within a semipermeable membrane [1]. This technology has proven a valuable strategy to facilitate a wide range of pharmaceutical and biomedical processes in both fundamental research and industrial applications including drug delivery, artificial organs, and cell therapy [2-9]. The key required characteristics of microcapsules for such applications include biocompatibility, adequate resistance to environmental constraints, appropriate membrane stability, and permeability [10-17]. In particular, preservation of structural integrity of microcapsules is crucial in many applications such as immunoisolation in cell transplantation [18]. Previous research has suggested that mechanically strong and durable capsules were less likely to rupture, thus prolonging in vivo functions of the encapsulated cells [11, 19-22].

Alginate, a polysaccharide isolated from brown algae, has been widely used in bioencapsulation due to its excellent biocompatibility and mild processing conditions. Addition of the outer poly-L-lysine (PLL)-alginate coating reduced the porosity of the alginate gel, rendering the alginate-PLL-alginate (APA) microcapsules promising as an immunoisolating device $[18,23-25]$. One of the main limitations accounting for graft failures using this system was the capsular fragility and short-term durability [20, 2629]. Insufficient membrane stability of the cell-containing microcapsules could lead to proteolytic degradation of the polyamino acid coating, destabilization of the alginate core matrix, and activation of the complement system, resulting in ultimate failure in immunoprotection [27]. Chitosan, a naturally derived polycation, was investigated as an alternative to PLL for microcapsule coating. Microencapsulation by the alginate-chitosan (AC) membrane, formed via electrostatic interactions between the two opposite charged polysaccharides, has been extensively studied for the delivery of drugs [30-36], proteins [37, 38], enzymes [39], growth factors [40], DNA [41, 42], live microbes [43$46]$, and cells $[47,48]$. However, the stability of the AC membrane remains limited [44, 49-52]. Hence, significant improvement in microcapsule chemistry is required for the delivery device to withstand long-term biological impediments. 
Covalent cross-linking of microcapsules constitutes an effective way to generate polymeric networks giving rise to high strength and resistance to chemical, proteolytic, and mechanical stresses $[53,54]$. Although enhancement in microcapsule stability using synthetic cross-linking reagents, such as bifunctional aldehydes [39, 55-57], carbodiimide (EDC) [50], and photosentitive molecules [58-60], has been reported, concerns about their cytotoxicity persist [61-65].

Genipin is an iridoid glucoside extracted from Gardenia fruits [66]. It has traditionally been used as a Chinese herbal medicine [67-71] and an edible colorant in the food industry [72]. In recent years, genipin has drawn considerable research interests as an alternative cross-linker due to its natural origin and low cytotoxicity, allowing for mild but effective chemical cross-linking [38, 63, 73-76, 7691]. We have earlier reported the use of genipin to introduce covalent links into the microcapsule membrane for live cell encapsulation [90, 92]. As a follow-up study, we present herein the characterization of the microcapsule structure and key physical characteristics including mechanical properties, resistance, permeability, and durability.

\section{Experimental}

2.1. Materials. Sodium alginate (low viscosity), bovine serum albumin (BSA, Mw 66 KD), lysozyme $(58,100$ units/mg protein), poly (L-lysine) hydrobromide (molecular weight, $\mathrm{Mv} 27.4 \mathrm{KD}$ ), and fluorescein isothiocyanate (FITC) labeled dextran ( $\mathrm{Mw} 4,20,40,70$, and $2000 \mathrm{KD}$ ) were obtained from Sigma-Aldrich, USA. Chitosan (low viscosity, $\mathrm{Mv}=7.2 \times 10^{4}$ by viscometry, degree of deacetylation at $73.5 \%$ by titration) and genipin were purchased from Wako BioProducts, USA. All other reagents and solvents were of reagent grade and used as received without further purification.

2.2. Preparation of GCAC Microcapsules. The GCAC microcapsules were prepared according to the protocol as earlier described [90]. Briefly, calcium alginate beads were formed by extruding an alginate aqueous solution $(15 \mathrm{mg} / \mathrm{mL})$ into a gelling bath containing $11 \mathrm{mg} / \mathrm{mL} \mathrm{CaCl}$. Coating with chitosan was performed by immersing the Ca-alginate beads in a chitosan solution $\left(10 \mathrm{mg} / \mathrm{mL}\right.$ in $\left.11 \mathrm{mg} / \mathrm{mL} \mathrm{CaCl}_{2}\right)$ for 30 minutes, resulting in the alginate-chitosan (AC) beads. Subsequently, the AC microcapsules were cross-linked by incubation in an aqueous solution of genipin $(1.0 \mathrm{mg} / \mathrm{mL})$ for 24 hours at $20^{\circ} \mathrm{C}$ and $4{ }^{\circ} \mathrm{C}$ (the latter of which used for the test in the simulated gastrointestinal fluid only). The resulting microcapsules were washed with deionized $\mathrm{H}_{2} \mathrm{O}$ prior to testing.

\subsection{Preparation of Microcapsules Containing Blue Dye or High} Molecular Weight Fluorescent Labeled Dextran. Microcapsules loaded with blue dye or FITC-dextran were prepared for the tests of long-term durability and enzymatic degradation, respectively. The preparation processes including alginate gelation, chitosan coating, and genipin cross-linking were performed using the aforementioned protocols except that a mixture of alginate solution with either a known amount of blue dye (Bleu ultramarine, Pb29, Kama Pigments), or with high molecular weight (HMW) FITC-dextran (FD2000, Mw $2000 \mathrm{KD}$ ) at a final dextran concentration of $2 \mathrm{mg} / \mathrm{mL}$ was used as the starting material.

2.4. Electron Microscopic Observations. Large Ca-alginate beads (approximately $1 \mathrm{~mm}$ in diameter) were prepared by extruding alginate solution into a $\mathrm{CaCl}_{2}$ receiving bath using a $1 \mathrm{~mL}$ syringe and a 27 gauge needle. Then the $\mathrm{AC}$ and GCAC beads were made according to the above-mentioned procedures. Beads were dehydrated by gradient ethanol and critical point drying (CPD, LADD Research Industries), and coated with Au-Pd using an Au-Pd sputtering coating unit (Hummer $\Pi$ Polaron Au Sputter Coater). A minimum of three beads randomly selected from each formulation batch were initially scanned to ensure batch homogeneity, and the microscopic structure examined by scanning electron microscopy (SEM) (FEG_SEM, Hitachi model S-4700). To characterize the inner membrane structure, the microcapsules were dehydrated, embedded in Epon and crosssectioned by using an ultramicrotome (Reichert Ultra Cut $\mathrm{AV})$ prior to microscopic observations under transmission electron microscopy (TEM) (Tecnai $12120 \mathrm{kV}$ TEM).

2.5. Swelling and Membrane Resistance. To assess the swelling behavior and membrane resistance, aliquots of microcapsules were submerged in $2 \mathrm{~mL}$ of physiological solution (PS, $0.9 \% \mathrm{NaCl}$ ) or phosphate buffered saline (PBS, $\mathrm{pH} 7.4$ ). The solution was refreshed every 2 hours in the first 8 hours and then once a day for up to 1 week. The morphology and physical integrity of the microcapsules were examined under an inverted light microscope (LOMO PC) at a magnification of $90 \times$. The microcapsule dimension was measured with an eyepiece micro-meter equipped on the microscope, and averaged from at least 8 beads per batch. The swelling ratio is expressed as percentage of diameter changed according to the following equation: \%Swelling $=\left(\mathrm{D}-\mathrm{D}_{0}\right) / \mathrm{D}_{0}{ }^{*} 100$, where $\mathrm{D}_{0}$ and $\mathrm{D}$ were microcapsule diameters before and after the incubation, respectively.

To examine the membrane resistance to citrate chelation, microcapsules were exposed to a sodium citrate solution $(50 \mathrm{mg} / \mathrm{mL})$ at room temperature for 24 hours. The changes in morphology were studied by using an optical microscopy.

To test the long-term membrane durability, blue dyeentrapped microcapsules were incubated up to 6 months at room temperature in PS containing sodium azide $(5 \mathrm{mM})$ to prevent microbial growth. The media were changed periodically. The morphology of the microcapsules was observed under the microscope, and images taken as records.

2.6. Osmotic Pressure Test and Mechanical Stability of Microcapsules. The mechanical stability of the microcapsules was examined by the osmotic pressure and mechanical shear tests. Osmotic stress was applied to microcapsules using a modification of a previously described procedure [93]. Specifically, the GCAC microcapsules were equilibrated for 
30 minutes in hypertonic solution $(10 \times, 5 \times, 2 \times$ or $1 \times$ of $0.85 \mathrm{wt} \%$ aqueous $\mathrm{NaCl}$ ) prior to transferal to a hypotonic medium (deionized $\mathrm{H}_{2} \mathrm{O}$ ), which led to a high osmotic pressure inside the microcapsules. During the following 1 hour, broken microcapsules were counted under an inverted microscope. In the mechanical stress experiments, microcapsules $(2 \mathrm{~mL})$ suspended in $10 \mathrm{~mL}$ deionized $\mathrm{H}_{2} \mathrm{O}$ were subjected to agitation $(600 \mathrm{rpm})$ for 3 hours. The percentage of destroyed microcapsules in at least three randomly picked observation fields was estimated under an optical microscope, and images taken as records. The experiments were performed in triplicate.

2.7. Membrane Permeability. In vitro permeability studies were performed to determine the ingress ratio of macromolecular markers and the microcapsule membrane molecular weight cutoffs (MWCO) using FITC-dextran (Mw 4, $20,40,70$, and $2000 \mathrm{KD}$ ) as fluorescent molecular weight standards and BSA as a model protein permeant.

2.7.1. Penetration of FITC-Dextran into Microcapsules. Microcapsules (approx 150 beads) were equilibrated overnight in PS at room temperature, followed by addition of an FITC-dextran solution $(150 \mu \mathrm{L}, 0.5 \mathrm{mg} / \mathrm{mL}$ dissolved in PS, with an exception of FD-4 at $1.0 \mathrm{mg} / \mathrm{mL}$ in PS due to the lower extent of FITC labeling). Incubation under light protection continued for 24 hours to reach equilibrium. Then, microcapsules along with the marker media were placed in a chambered coverglass system (Lab-TeK). The diffusion of FITC-dextran into the microcapsules was investigated by confocal laser scanning microscopy (Zeiss LSM 510, Jena, Germany) equipped with a Zeiss Axiovert $100 \mathrm{M}$ microscope. An argon-ion laser was used at an excitation of $488 \mathrm{~nm}$ and the fluorescence was detected with the filter block BP500-550IR. For quantitative evaluation, rectangles with an area of $0.05 \mathrm{~mm}^{2}$ at an equatorial, optical section of microcapsules inside the microcapsules and in the surrounding media were defined. Mean pixel grey values representing the relative fluorescence intensities were acquired using LSM 510 software command "Topography". Standard deviations of pixels within the detected areas were consistently below 9 to ensure homogeneity of the fluorescence signals in the tested regions. Diffusion of dextran into ten individual capsules per batch was assessed and expressed as percent of fluorescence intensity in the microcapsule confines relative to that in the incubation solution (background reading). Microcapsule membranes with dextran diffusion less than $5 \%$ were considered cutoff to the tested marker.

2.7.2. Penetration of BSA into Microcapsules. Immediately after BSA solution $(1.5 \mathrm{mg} / \mathrm{mL}$ in $1.5 \mathrm{~mL}$ PS) was added to the vials containing the tested microcapsules $(3.0 \pm 0.01 \mathrm{~g})$ and placed in an Environ shaker with gentle rotation at a speed of $125 \mathrm{rpm}$, the concentrations of BSA remaining in the supernatant was monitored for up to 8 hours using the Bradford method. The absorbance at $595 \mathrm{~nm}$ was recorded using a $\mu$ Quant Universal Microplate Spectrophotometer
(Bio-Tek Instruments, Inc.) and the protein concentration was determined using a BSA standard curve. The BSA diffusion profile was plotted as relative BSA remaining in the medium as a function of incubation time.

\subsection{BSA Encapsulation and In Vitro Sustained Release}

2.8.1. BSA Encapsulation. To prepare the BSA encapsulated microcapsule, BSA was first dissolved in PS and mixed with alginate solution to give a final concentration of $15 \mathrm{mg} / \mathrm{mL}$ for both BSA and alginate. The mixture was extruded and droplets were gelled in a $\mathrm{CaCl}_{2}$ receiving bath $(11 \mathrm{mg} / \mathrm{mL})$ for 15 minutes. The subsequent coating with chitosan and cross-linking by genipin were performed according to the aforementioned protocol. Prior to assessment of protein release the microcapsules were equilibrated overnight in a physiological solution containing $15 \mathrm{mg} / \mathrm{mL}$ BSA to compensate for possible BSA loss during preparation.

2.8.2. In Vitro Release of Encapsulated BSA. The BSA loaded microcapsules $(0.20 \mathrm{~g})$ were suspended in $2.0 \mathrm{~mL} 0.01 \mathrm{M}$ phosphate buffered saline (PBS, pH 7.4) with gentle rotation in an ENVIRON shaker at $37^{\circ} \mathrm{C}$. At various time points, supernatant $(1.0 \mathrm{~mL})$ was withdrawn to determine the release of BSA by the Bradford assay as described above, and the medium was replaced with fresh PBS. Results of accumulated protein released from triplicate experiments were plotted as a function of incubation time.

2.8.3. BSA Stability Assay. To confirm the integrity and stability of the encapsulated BSA, freshly made BSA-containing microcapsules were immersed in a sodium citrate aqueous solution (10 $\mathrm{wt} \%)$, followed by pressing the bead suspension through needles with gradually increasing gauge (from 18 to $27 \mathrm{G}$ ) to break the capsules and liberate the entrapped BSA. Subsequently, the suspension was centrifuged at $5000 \mathrm{~g}$ for 5 minutes and the supernatant was pressed through a $0.22 \mu \mathrm{m}$ syringe filter. The clear filtrate was analyzed by a highperformance liquid chromatographic system (HPLC, Varian Inc. Canada) equipped with a column of Biosep-SEC3000 (Phenomenex). The mobile phase, $50 \mathrm{mM}$ phosphate buffer solution ( $\mathrm{pH} 6.8$ ), was prefiltered through $0.22 \mu \mathrm{m}$ vacuumdriven filter unit (Millipore, Japan) and run at a flow rate of $0.5 \mathrm{~mL} / \mathrm{min}$ at room temperature. The injection loop was set at $20 \mu \mathrm{L}$ and UV detection at $280 \mathrm{~nm}$. A standard BSA solution was used as reference.

2.9. In Vitro Degradation by Lysozyme. A known amount $(0.5 \pm 0.01 \mathrm{~g})$ of the microcapsules containing high molecular weight fluorescent-labeled dextran $(2000 \mathrm{KD})$ were placed in amber vials containing lysozyme solutions $(2.0 \mathrm{~mL})$ at different concentrations $(15 \mu \mathrm{g} / \mathrm{mL}, 150 \mu \mathrm{g} / \mathrm{mL}$, and $15 \mathrm{mg} / \mathrm{mL}$ ) in PBS and incubated at $37^{\circ} \mathrm{C}$ in a platform shaker with gentle rotation of $100 \mathrm{rpm}$ for either 7 or 30 days. The leakage of fluorescent marker from the microcapsules was assessed as indicative of membrane defects induced by lysozyme degradation and erosion. Supernatant $(0.2 \mathrm{~mL})$ 


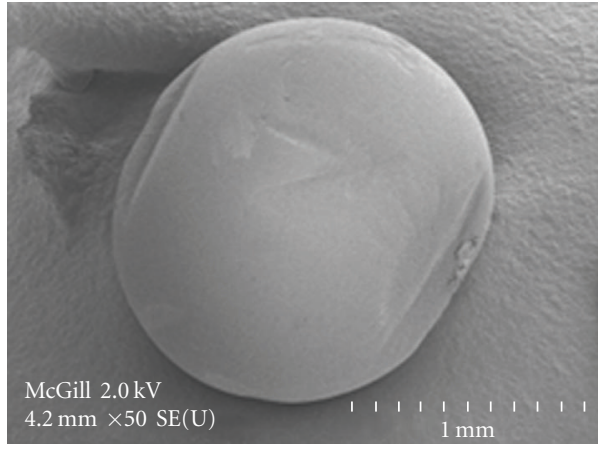

(a)

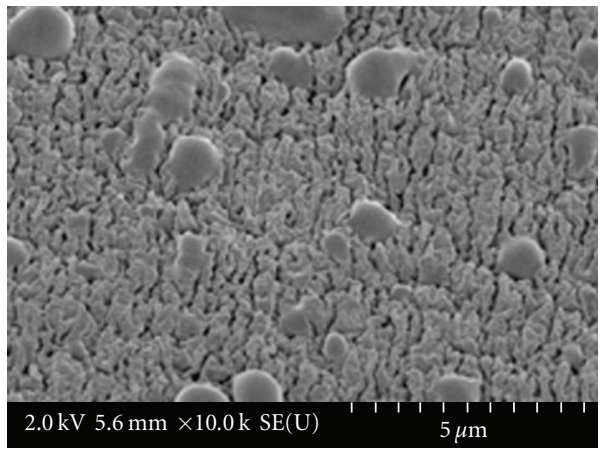

(c)

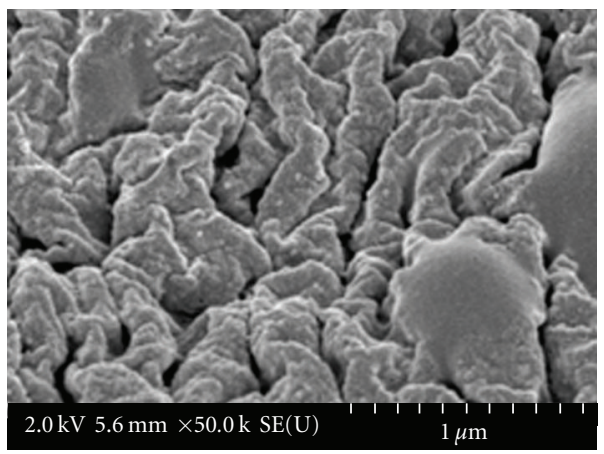

(e)

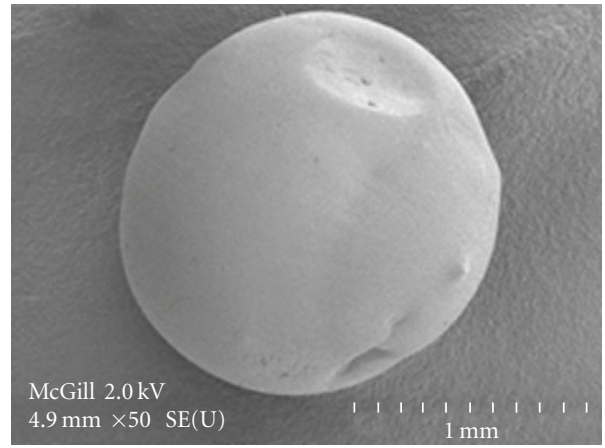

(b)

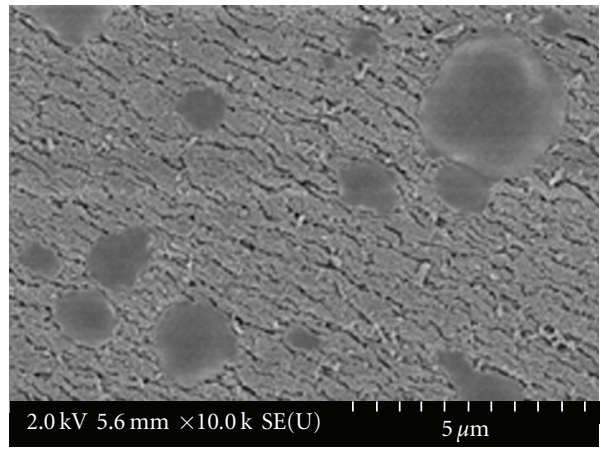

(d)

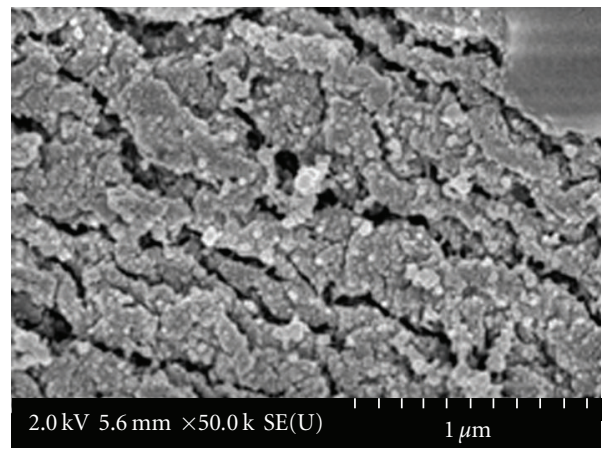

(f)

Figure 1: SEM images of the AC (a), (c), (e) and GCAC (b), (d), (f) microcapsules. (a)-(b): overview at 50×; (c)-(d) and (e)-(f): surface structure at $10 \mathrm{kx}$ and $50 \mathrm{kx}$, respectively.

was withdrawn at different intervals and assessed spectrofluorometrically using a Microplate Fluorescence Reader (FLx800, Bio-Tek Instruments, Inc.) with the absorption and emission wavelengths at 485 and $528 \mathrm{~nm}$, respectively. The volume of the media was kept constant by adding fresh lysozyme solution after sampling. Data are presented as mean \pm s.d. from triplicate experiments.

\subsection{Membrane Resistance to Simulated Gastrointestinal} Fluids. To examine the potential of microcapsules for oral applications, the simulated gastric fluid (SGF, pH 1.2) and the simulated intestinal fluid (SIF, $\mathrm{pH}$ 7.5) were prepared according to United States Pharmacopoeia XXII protocol, and used to test the microcapsule resistance. The morphological changes of the tested microcapsules were observed by optical microscopy (LOMO PC), and microphotographs were recorded using a digital camera (Canon Power shot G2).

\section{Results and Discussion}

3.1. Surface and Internal Structure of Microcapsules. The surface and internal structure of the microcapsules were examined by electron microscopy and images are shown in Figures 1-4. We found that these microcapsules were essentially spherical in geometry, possessing a homogenous, smooth, and compact structure on the surface (Figure 1). The GCAC microcapsule had a denser and smoother surface than the AC membrane (Figures 1(c) and 1(d)), though sporadic small nubs were seen in both cases. Preliminary energydispersive $\mathrm{x}$-ray (EDX) analysis did not show differences 

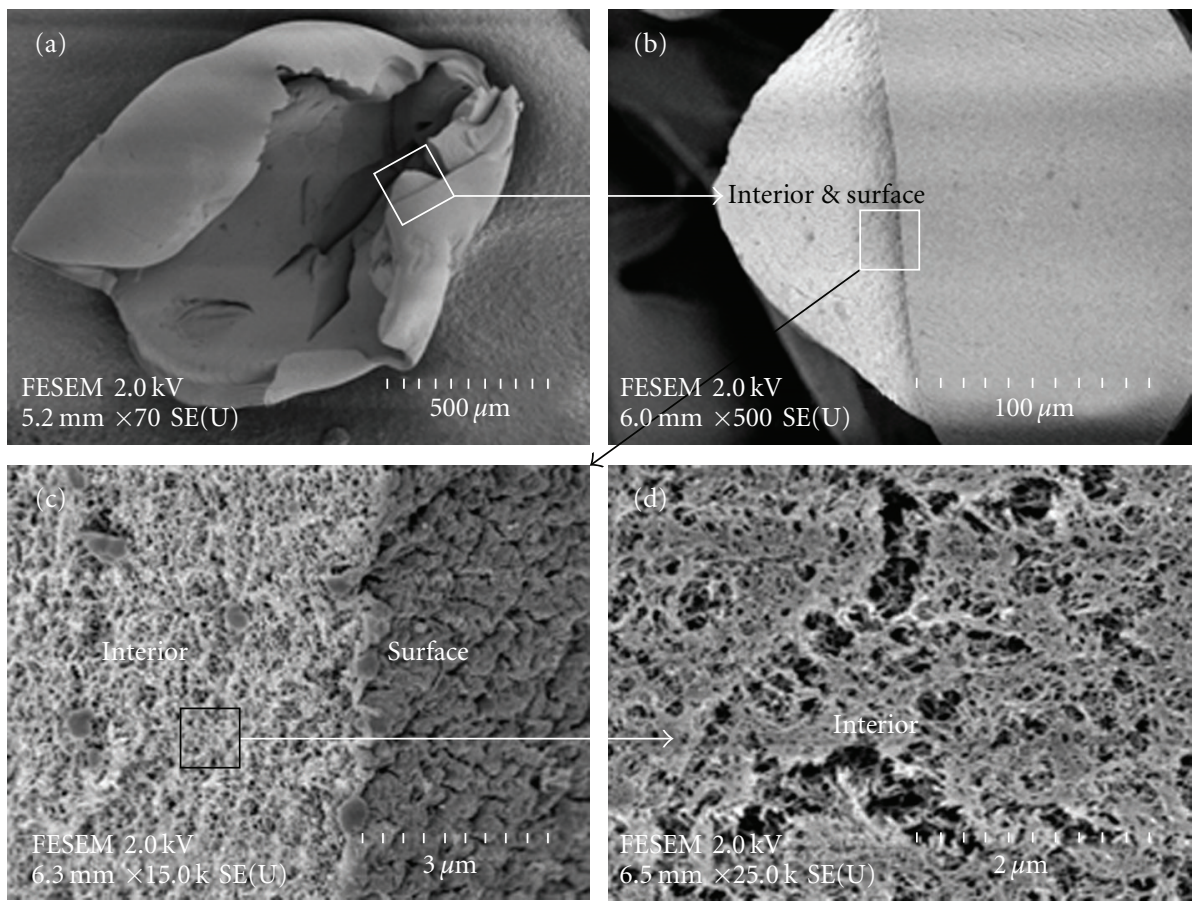

FIGURE 2: SEM images of the surface and interior structure of the AC microcapsules. (a): overview at $70 \times$; (b): white square in (a) at a higher magnification at $500 \times$; (c): square in (b) at $15 \mathrm{kx}$; and (d): square in (c) at $25 \mathrm{kx}$.

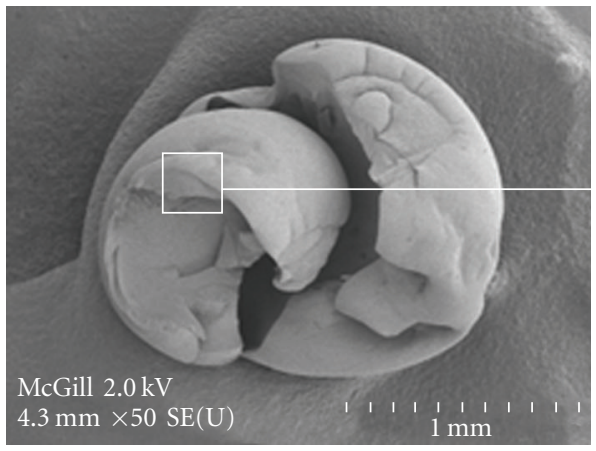

(a)

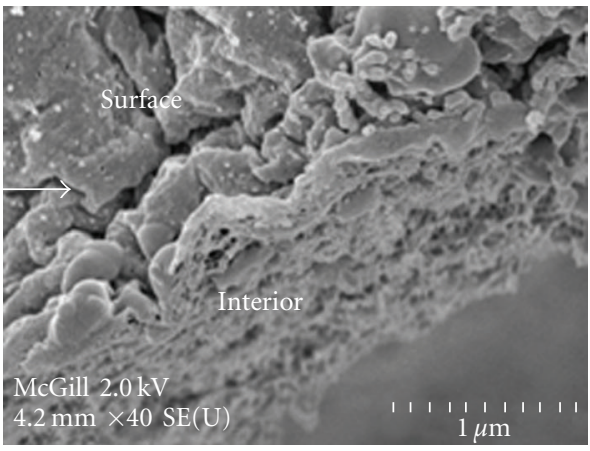

(b)

Figure 3: SEM images of the surface and interior structure of the GCAC microcapsules. (a): full view at 50×; and (b): surface and interior structure at $40 \mathrm{kx}$.

in chemical compositions on these small nubs when compared to the other regions of the membrane. At higher magnifications, the presence of clusters and small spheres on the cross-linked surface was observed (Figure 1(f)). Porous structure was found inside the microcapsules without discernible differences in porosity and density of the network between the AC and GCAC capsules (Figures 2 and 3). The internal morphology of the microcapsule membranes at the boundary regions was assessed by TEM. In comparison to the alginate (Figures 4(a) and 4(b)) and AC capsules (Figures $4(\mathrm{c})$ and $4(\mathrm{~d})$ ) where a more granular pattern of structure was observed, a smoother and denser structure was seen for the GCAC membranes (Figures 4(e) and 4(f)). These structural differences were most likely caused by different membrane chemistries.
3.2. Effect of Genipin Cross-Linking on Microcapsule Swelling and Resistance. Alginate is highly hydrophilic because of the presence of $-\mathrm{OH}$ and $-\mathrm{COOH}$ groups in its chain. At neutral $\mathrm{pH}$, water penetrates into the chains of alginate to form hydrogen bridges through the $-\mathrm{OH}$ and $\mathrm{COO}^{-}$groups, and fills up the space along the chains and/or the centre of wide pores or voids [94]. As a consequence, the alginate beads tend to swell substantially. Additional swelling and destabilization are promoted by the presence of non-gelling ions and chelators, such as sodium, magnesium, phosphate, lactate, and citrate. For example, a substantial quantity of sodium and phosphate ions in physiological conditions induce osmotic swelling. Chelation of the bound crosslinking calcium ions results in the loss of the egg-box structure and dissolution of the alginate matrix [22, 95]. Previous 

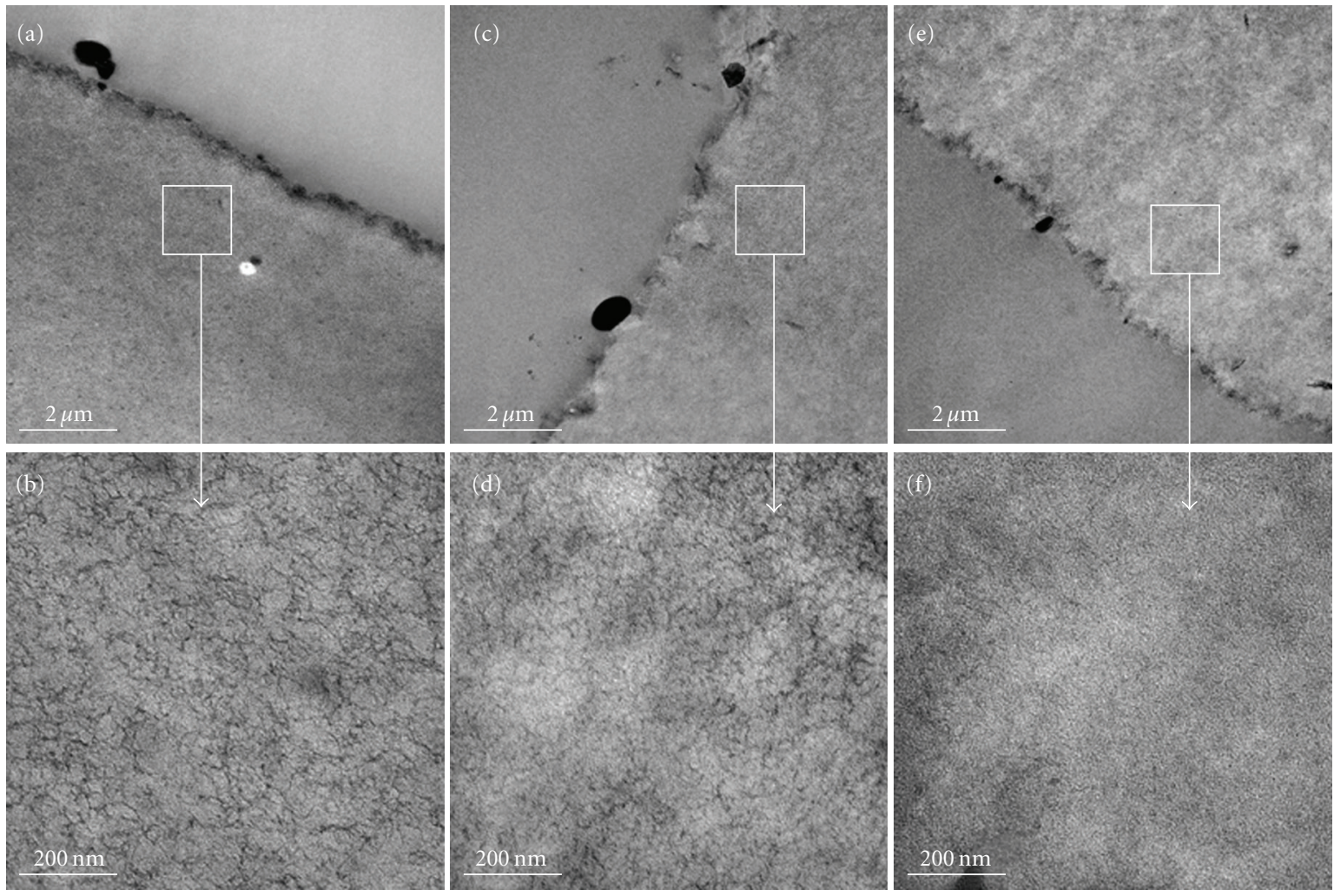

Figure 4: TEM images of the microcapsules. (a)-(b): alginate bead; (c)-(d): AC microcapsule; (e)-(f): GCAC microcapsule. (a), (c), and (e) (upper row) show the boundary regions of the microcapsule membrane; (b), (d), and (f) (lower row) depict the structural details of the square regions in the corresponding images in the upper row. Bars $=2 \mu \mathrm{m}$ (a), (c), (e), and $0.2 \mu \mathrm{m}$ (b), (d), (f).

studies suggested that creating a strong membrane and minimizing the matrix swelling may stabilize the alginatebased microcapsules [22, 27, 96, 97]. In our study, morphological changes in microcapsules exposed to non-gelling media and citrate chelation were investigated. Results showed that the GCAC microcapsules remained intact and swelled $2.7 \pm 1.8 \%$ and $11.7 \pm 1.4 \%$ in PS and PBS, respectively. Both AC and APA microcapsules experienced substantial swelling in PBS, increasing in size by approximately $46 \%$ and $80 \%$, respectively (data not shown). After 24 hours of citrate treatment, the AC microcapsules showed significant swelling with worn out and thinner membrane though resistant against complete dissolution (compare Figure 5(a) with Figure 5(b)). In contrast, the GCAC microcapsules underwent limited swelling and remained morphologically stable (compare Figure 5(c) with Figure 5(d)). In addition, the cross-linked microcapsules retained their structural integrity for at least 6 months in PS, compared to the AC capsules showing membrane defection (roughly 8\%) over the same period of investigation (Figure 6). These observations demonstrate the enhancement of microcapsule resistance and durability by the covalent links on the membrane.

\subsection{Mechanical Stability of GCAC Microcapsule Membrane.} Mechanical properties of microcapsule membranes are of key importance for their integrity preservation and in vivo performance. It was previously reported that microcapsules with strong membranes were more durable and less likely ruptured, which allows for prolonged functions of the encapsulated cells [20,21,27]. Despite being crucial, precise determination of the microcapsule mechanical strength is difficult because of the size (generally $100 \mu \mathrm{m}$ to $2 \mathrm{~mm}$ in diameters) [98] and fragile nature of the microcapsule. A number of assessment techniques have been explored [13, 16, $28,93,96,99$ ], but standard testing methods have yet to be established. In this study, the membrane strength was evaluated by subjecting the microcapsules to osmotic pressure and mechanical agitation. It was found that after exposure to an osmotic shock, none of the GCAC microcapsules burst, in contrast to the complete fracture of the APA capsules (data not shown). In the mechanical shear test, the vigorous agitation accelerated the breakage of the microcapsules. After 3 hours of continuous mechanical agitation, the APA microcapsules became totally fragmented; $70-80 \%$ of the AC beads were ruptured; whereas approximately $30 \%$ of the cross-linked microcapsules were destroyed (Figure 7). Noticeably, some of the GCAC microcapsules had changed into an elliptical shape under mechanical force, indicating the elasticity of the cross-linked capsules (Figure 7(c)). This improvement in mechanical stability was correlated with the reduced swelling of the GCAC capsules, showing that covalent cross-linking by genipin considerably stabilized the microcapsules. 


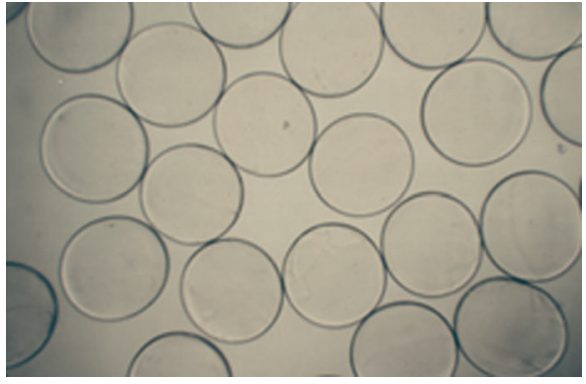

(a)

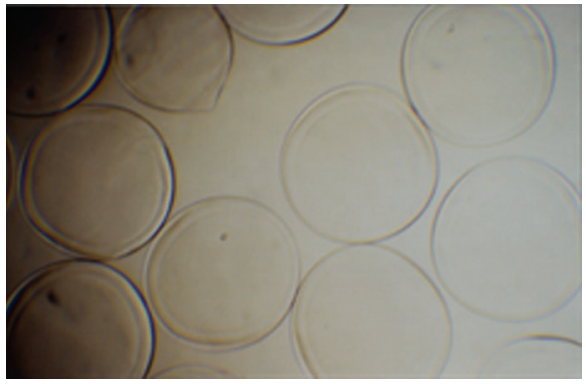

(b)

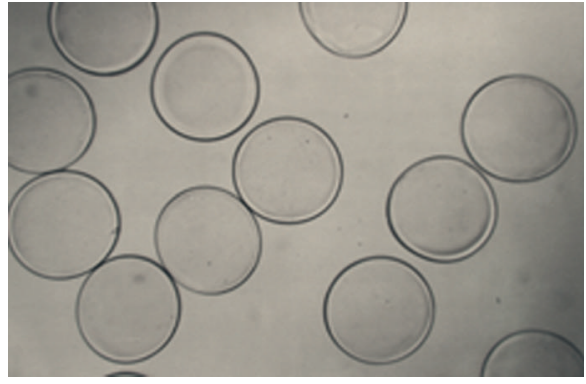

(c)

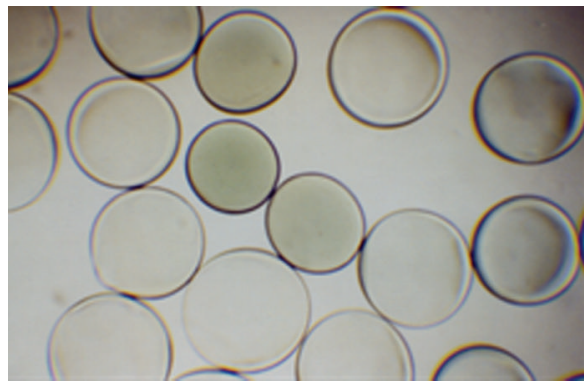

(d)

Figure 5: Microphotographs of the AC (a), (b), and GCAC (c), (d) microcapsules before (a), (c), and after (b), (d) chelation by sodium citrate $(50 \mathrm{mg} / \mathrm{mL})$ for 24 hours. Original magnifications: $35 \times$.

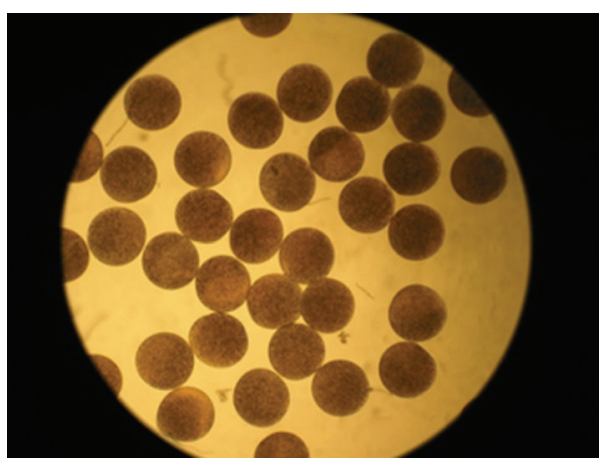

(a)

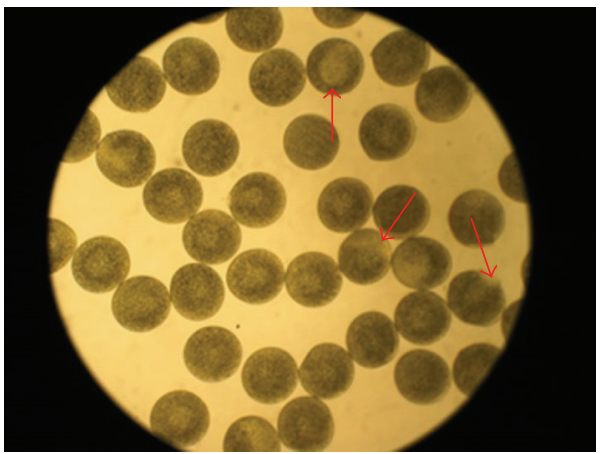

(c)

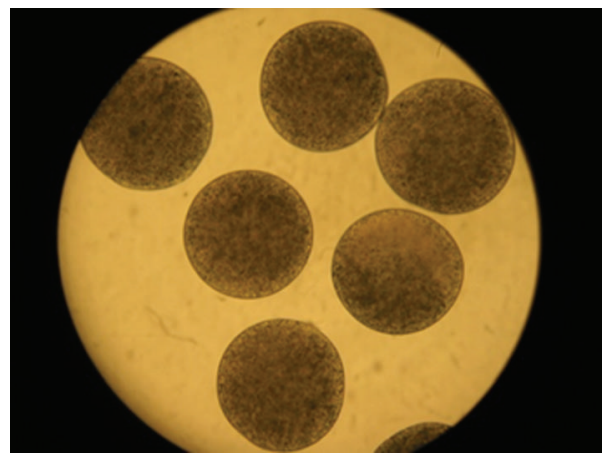

(b)

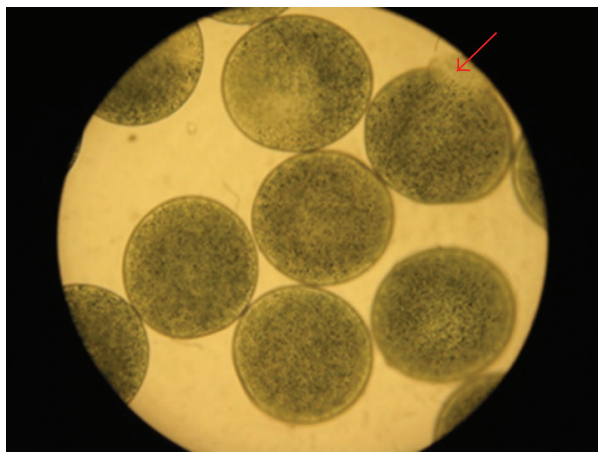

(d)

Figure 6: Morphological stability of the GCAC (a), (b), and AC (c), (d) microcapsules containing blue dye after incubation in saline for 6 months. Red arrows indicate defects of the microcapsules. Original magnifications are $35 \times$ (a), (c) or 90× (b), (d). 


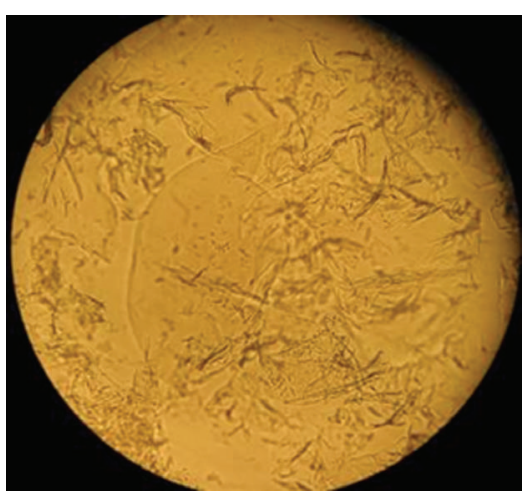

(a)

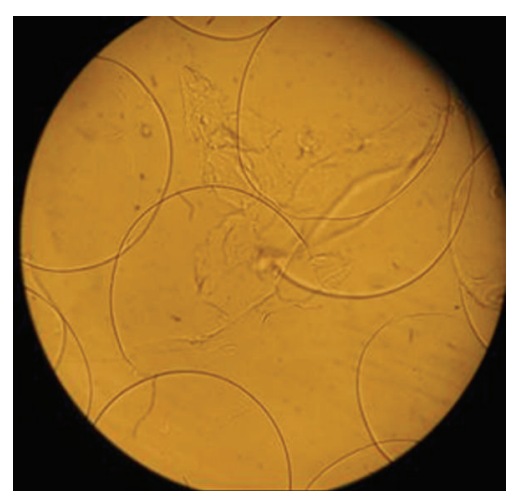

(b)

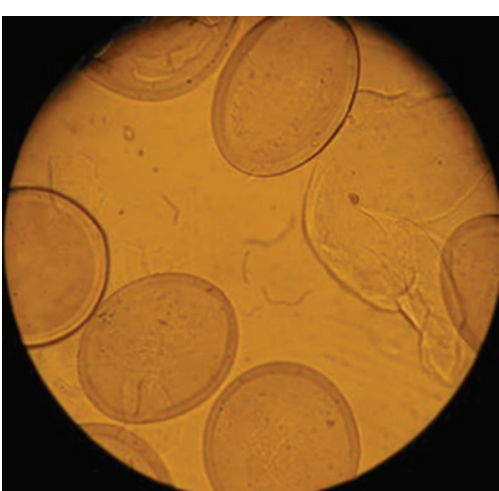

(c)

Figure 7: Microphotographs of APA (a), AC (b), and GCAC (c) microcapsules after being subjected to mechanical agitation (600 rpm) for 3 hours. Original magnifications: $90 \times$.

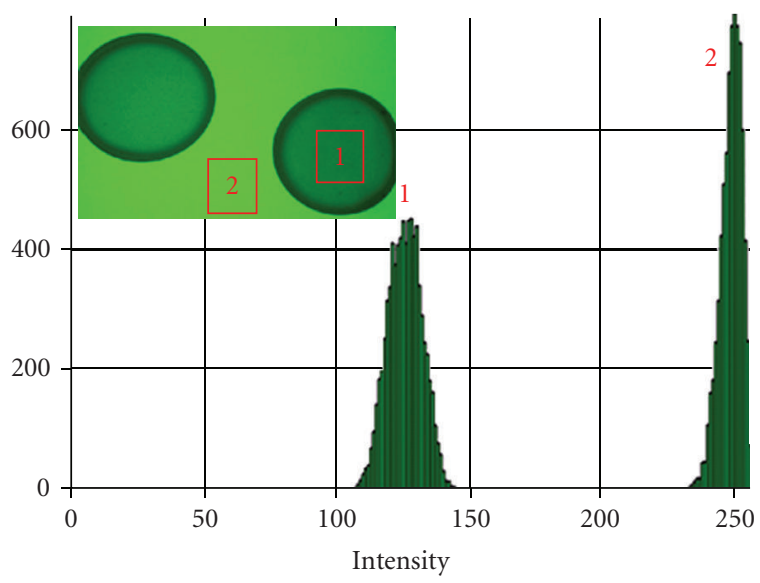

Figure 8: Analysis of fluorescence intensity inside and outside the microcapsule incubated in the solution of a fluorescent marker (20 KD FITC-dextran, $0.5 \mathrm{mg} / \mathrm{mL}$ ). Peak 1 and Peak 2 in the intensity profile correspond to the fluorescence intensity inside (square 1) and outside (square 2) the microcapsule outlined in the insert, respectively.

3.4. Permeability of Microcapsules. In cell microencapsulation, live cells are isolated from the external environment by an artificial, semipermeable membrane, which should allow for ingress of oxygen and nutrients, and egress of waste products and therapeutic molecules. Proper encapsulated cell functions require strict control over permeability of the microcapsule membrane. In permeability research, the use of neutral polysaccharide molecular weight standards precludes the problems of absorption, aggregation, and other charge/hydrophobic interactions, while proteins are thought to be more appropriate in determining the permeability of microcapsules designed for biological systems [100, 101]. In our study, permeability measurements were carried out with individual microcapsules using confocal laser scanning microscopy (CLSM) to examine the ingress of fluorescent dextran markers, and by batch experiments detecting the decrease in concentration of the protein marker in incubating media containing plain microcapsules.

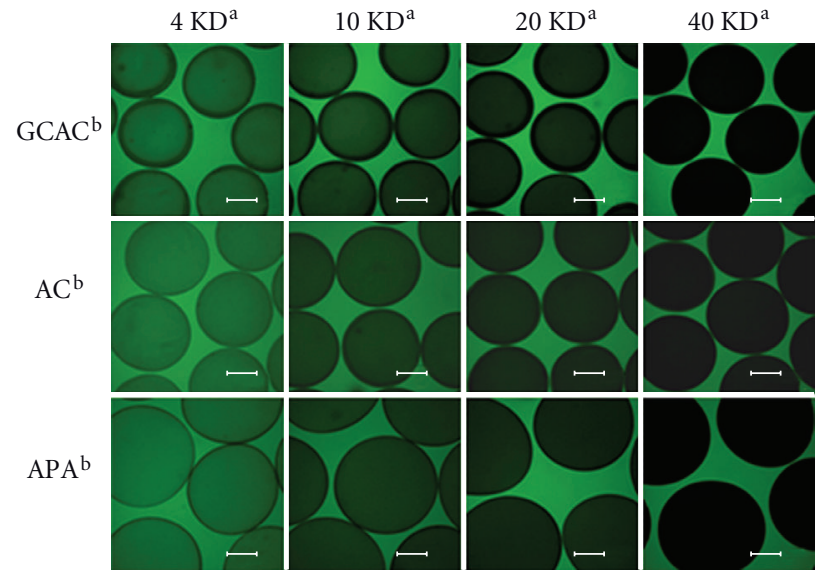

FIGURE 9: Visualization of FITC-dextran permeation into microcapsules by CLSM. a Molecular weight of FITC-dextran; ${ }^{\mathrm{b}}$ Type of microcapsules. Bars $=200 \mu \mathrm{m}$.

Dextran is a linear and neutral polysaccharide, whereas globular BSA bears negative charges at $\mathrm{pH}>5.0(p I=$ 4.8 ) and hydrophobic character. Results from our dextran experiments using CLSM are shown in Figures 8-10. Figure 8 depicted the significant difference in light intensity within tested regions of the two red rectangles (mean pixels 125 versus 242 ), suggesting the nonhomogeneous dissemination of FITC-dextran $(20 \mathrm{KD})$ inside and outside the microcapsule. The representative CLSM images shown in Figure 9 demonstrated that the dextran ingress was significantly reduced with increasing molecular weights of fluorescent markers. Irrespective of microcapsules, low $\mathrm{Mw}$ dextran $(4 \mathrm{KD})$ infiltrated to the interior of the microcapsules at a great extent (diffusion ratio $>70 \%$ ), whereas permeation of larger dextrans, $40 \mathrm{KD}$ and $70 \mathrm{KD}$, was greatly restricted, with the inflow ratio around $20 \%$ and below $5 \%$, respectively (Figure 10). The cut-off for the GCAC membrane was on the order of $70 \mathrm{KD}$ (for FITC-dextran), and same as for the APA and AC microcapsules, which corroborated with the published results [100, 102-106]. 


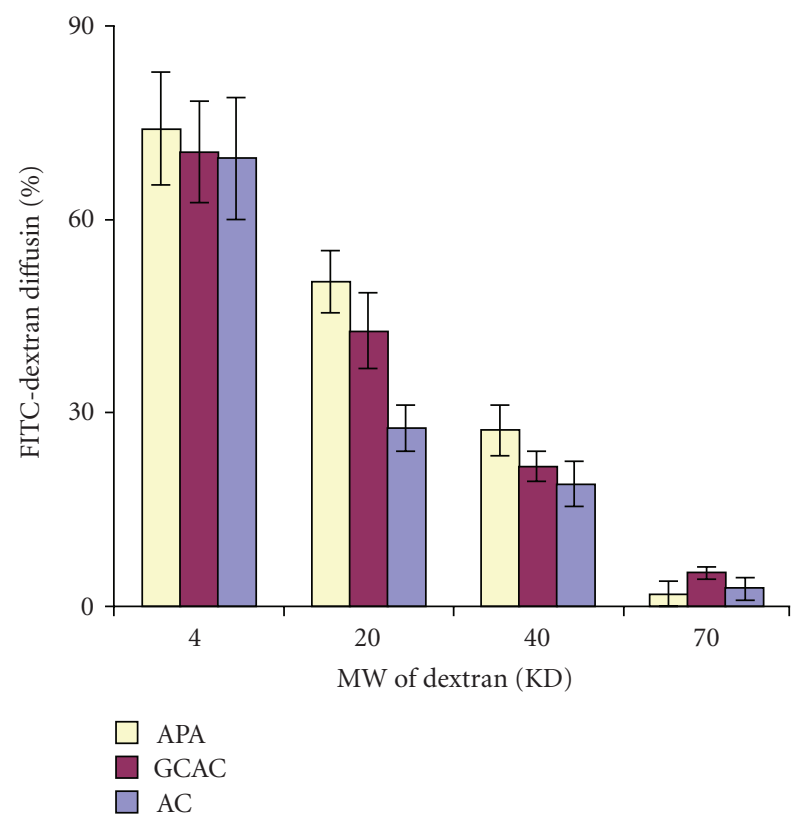

Figure 10: Diffusion of FITC-dextran into microcapsules as a function of dextran molecular weight.

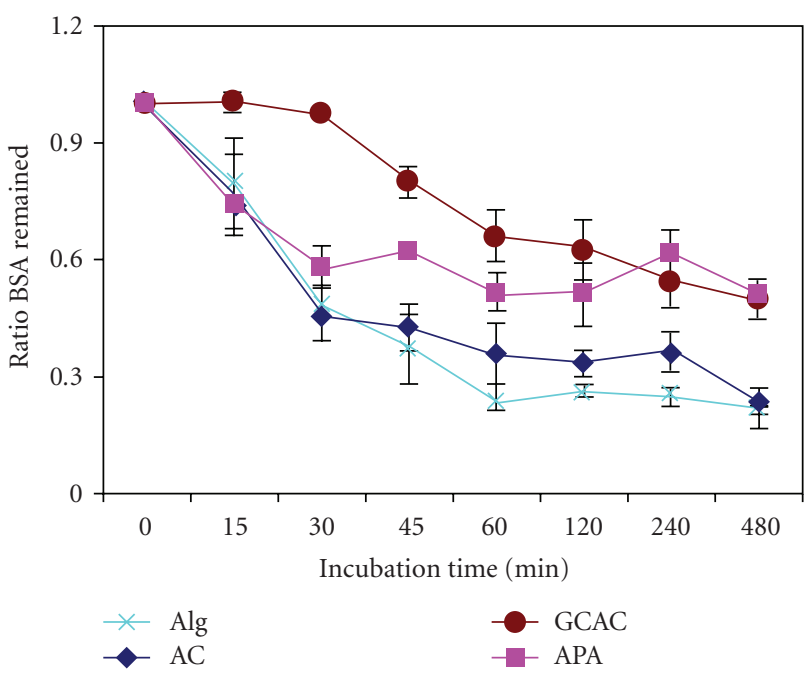

Figure 11: Penetration of BSA into microcapsules as a function of incubation time.

As the diameter of BSA may correspond to dextran with molecular weight of $\sim 20 \mathrm{KD}$, which is below the abovedescribed exclusion limit, BSA should theoretically penetrate the studied microcapsule membranes. Our observation on BSA diffusion confirmed this postulation. Despite initial retardation, BSA was able to diffuse into the GCAC microcapsules, as seen by a gradual decline of BSA remaining in the media (Figure 11). After 4 hours, the BSA infiltration reached a similar level to that for the APA microcapsules, with $\sim 55 \%$ of BSA remaining in the media. In the GCAC and AC systems, the membrane thickness was mainly governed by the binding of chitosan [92]. This may

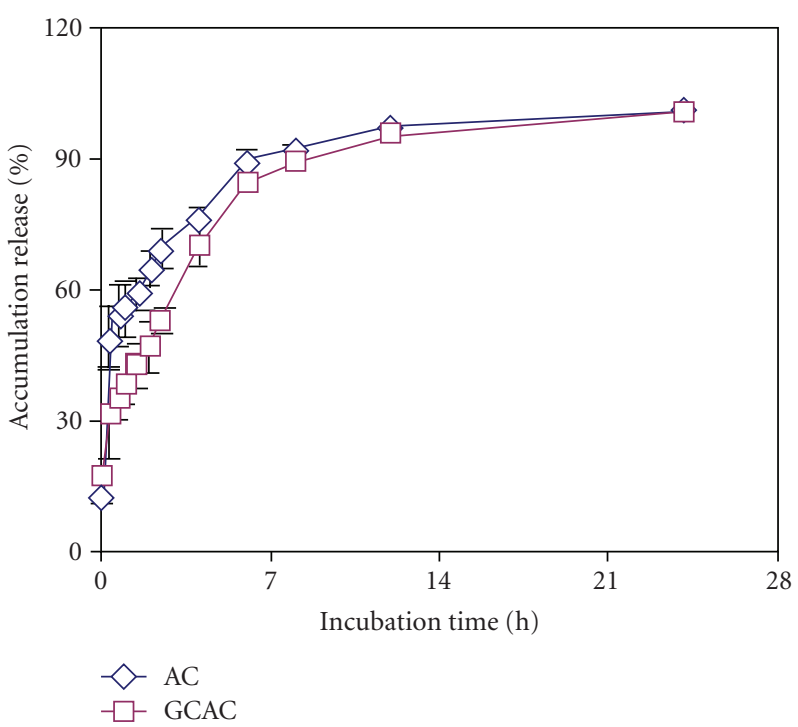

FIGURE 12: Cumulative release of encapsulated BSA from microcapsules as a function of incubation time.

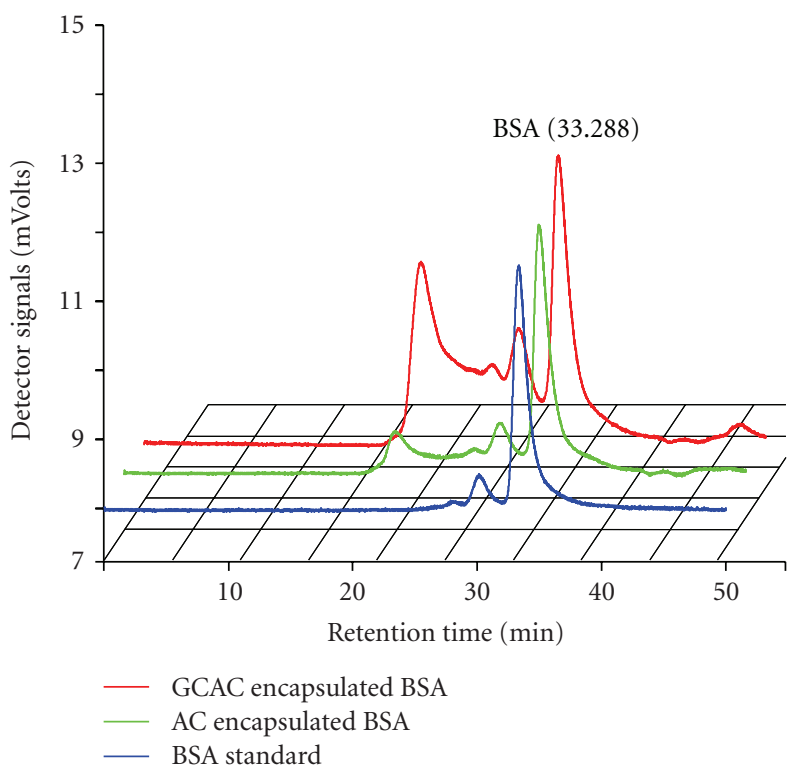

FIGURE 13: HPLC chromatographs of the encapsulated BSA in the GCAC and AC microcapsules as compared to BSA standard.

account for their similar permeability for dextran diffusion (Figure 10). The retardation of protein infiltration to the GCAC microcapsules shown in Figure 11 may be ascribed to the transport hindrance caused by the denser network structure of the genipin cross-linked membrane. The effects of genipin cross-linking variables on the permeability of the GCAC microcapsules were also investigated, and no statistically significant differences on the membrane cutoffs were detected within the tested ranges (data not shown). The above findings indicated that the covalent cross-linking treatment by genipin modulated the diffusion kinetics of the permeants but did not alter the membrane MWCO cutoffs. 


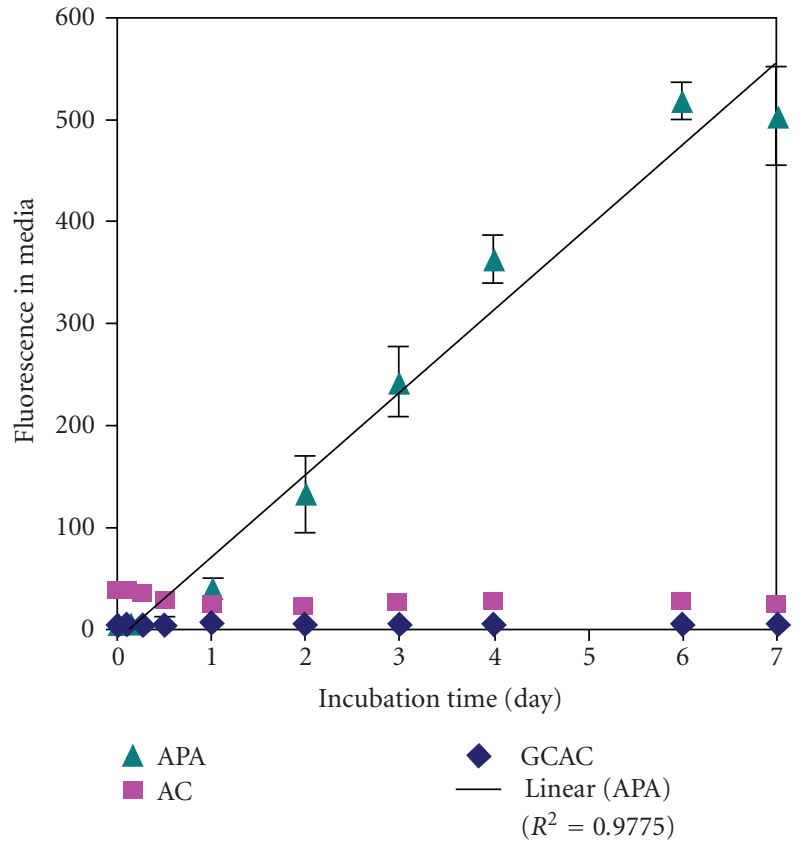

(a)

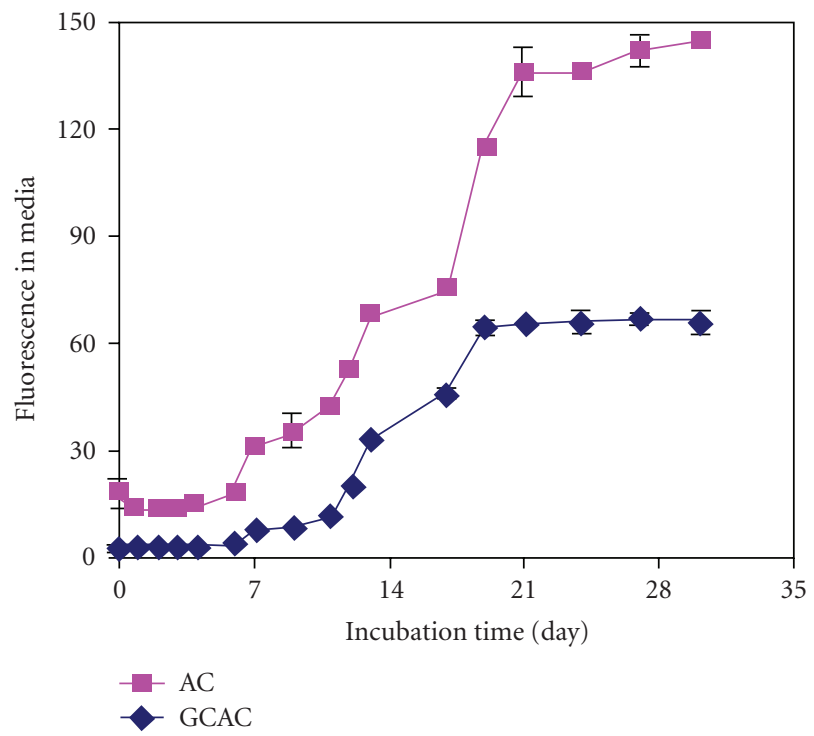

(c)

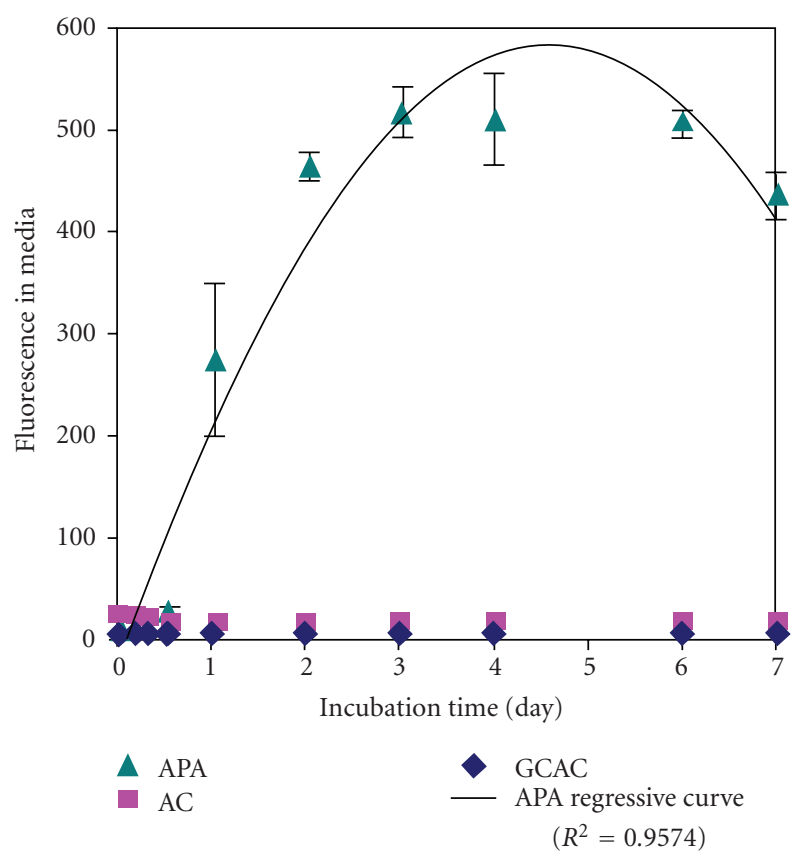

(b)

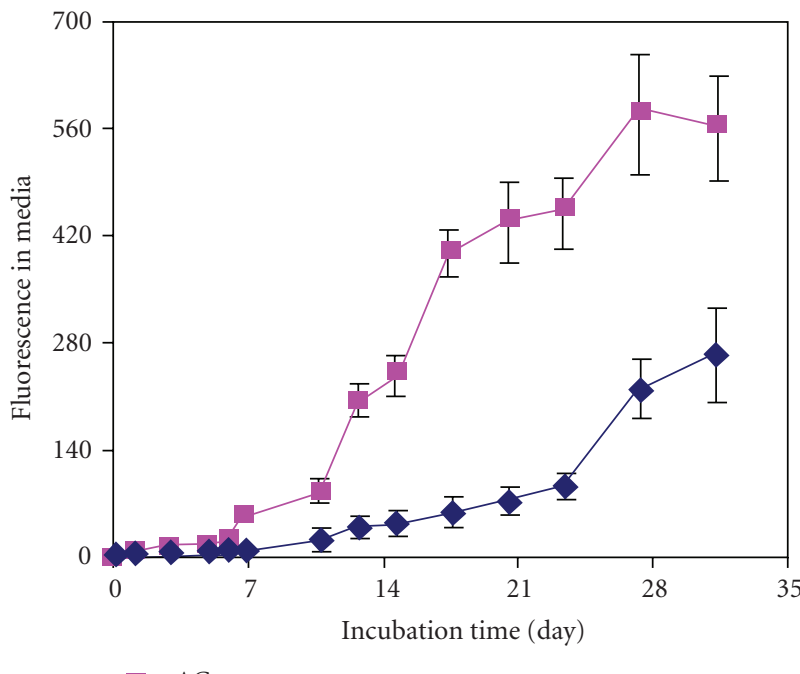

$\mathrm{AC}$

GCAC

FIGURE 14: Leaking of the entrapped FITC-dextran (MW 2000 KD) from microcapsules incubated in lysozyme solution at the concentrations of (a): $15 \mu \mathrm{g} / \mathrm{mL}$; (b)-(c): $0.15 \mathrm{mg} / \mathrm{mL}$; (d), $15 \mathrm{mg} / \mathrm{mL}$. Note the scale differences in both $\mathrm{x}-\mathrm{y}$ axes.

3.5. Sustained Release of Encapsulated BSA. The permeability characteristics of the chitosan-based microcapsules were further examined by the release profiles of the encapsulated BSA. As shown in Figure 12, prolonged release of BSA from both the AC and GCAC microcapsules was evidenced. As well, the genipin cross-linked membrane delayed the release of BSA for an appreciable period of time. Specifically, the cumulative percentage of BSA released from the GCAC and AC capsules was $38.1 \%$ and $55.5 \%$ in the first 1 hour, respectively. Thereafter, these numbers increased to $46.8 \%$ versus $69.5 \%$ in 2 hours, and $70.4 \%$ versus $76.7 \%$ in 4 hours, and both above 95\% after 12 hours (Figure 12). This delay in BSA release, which was consistent with the results obtained from the BSA ingress experiments, could be a result of transport obstruction in the GCAC membranes generated by the genipin-chitosan cross-links.

Additionally, the loss of stability of the encapsulated protein is one of the concerns regarding protein immobilization and drug delivery. In the present research, the stability of microencapsulated BSA was further examined by the integrity change reflected in their chromatographs. One can see in Figure 13 that the entrapped BSA in both 


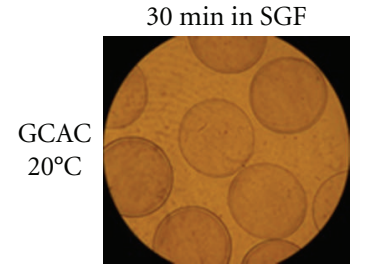

(a)

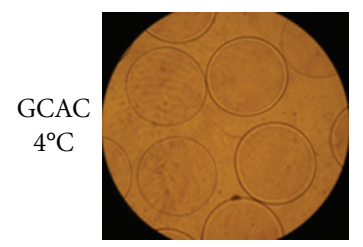

(f)

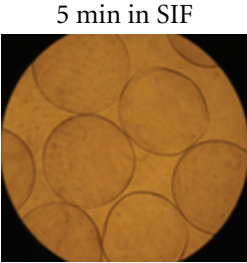

(b)

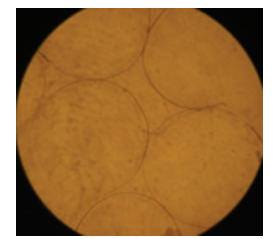

(g)

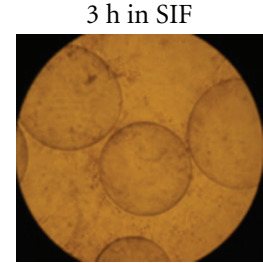

(c)

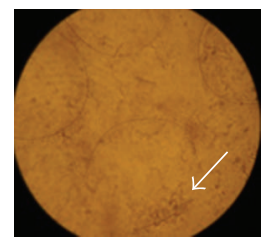

(h)

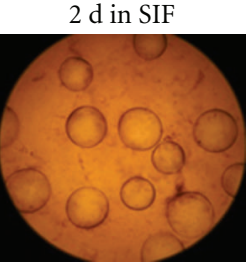

(d)

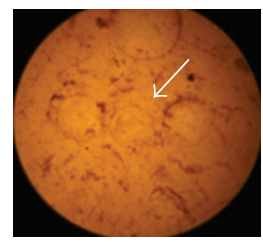

(i)

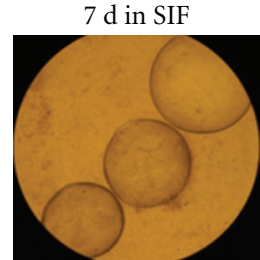

(e)

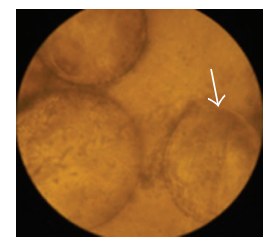

(j)

FIGURE 15: Microphotographs of GCAC microcapsules cross-linked at $20{ }^{\circ} \mathrm{C}$ (a)-(e) and at $4{ }^{\circ} \mathrm{C}$ (f)-(j) after sequential incubation in simulated gastric fluid and simulated intestinal fluid. Original magnifications were $90 \times(\mathrm{a})-(\mathrm{c}),(\mathrm{e}),(\mathrm{f})-(\mathrm{h})$, and (j) and $35 \times(\mathrm{d})$ and (i).

$\mathrm{AC}$ and GCAC microcapsules showed a peak equivalent to the standard protein in terms of retention time and peak shape. The presence of some large molecules with molecular weights higher than the BSA standard was also detected at earlier elution time in the chromatographs of both BSA-containing microcapsules, and a higher amount of these unknown molecules was found inside the GCAC microcapsules. These large molecules, present in the GCAC microcapsules in a greater quantity, may likely arise from the BSA-chitosan complex, the genipin cross-linked BSA, or other impurities. Although the integrity of the encapsulated BSA was confirmed by HPLC, whether the genipin treatment would affect the enclosed proteins need further investigation.

3.6. In Vitro Degradation by Lysozyme. HMW FTIC-dextran (2000 KD) was encapsulated as a tracer to study the enzymatic degradation of microcapsule membrane in vitro. Being a large polymer in this size, this fluorescent probe should indefinitely be withheld inside the intact microcapsules and could not spread out unless the membranes became defected. A universal enzyme lysozyme was used in this study to decompose microcapsule membranes, and the leaching of encapsulated dextran induced by corrosion and degradation of the microcapsule membranes was examined. Exposure of the fluorescent tracer-loaded APA microcapsules to lysozyme $(15 \mu \mathrm{g} / \mathrm{mL})$ resulted in an increase in the media's fluorescence, proportional with incubation time $\left(R^{2}=0.9775\right.$, Figure $\left.14(\mathrm{a})\right)$ and reaching the intensity of 243 and 503 at day 3 and 7, respectively. With 10 times more concentrated lysozyme, the leaking of FITC-dextran occurred more rapidly, from 9,272 , to 513 at time 0 , day 1 and day 3, respectively (Figure 14(b)). Conversely, leaking of encapsulated dextran from the AC and GCAC microcapsules was negligible (Figures 14(a) and 14(b)) under the same challenging condition, with membrane integrity preserved over the 7-d experimental period (data not shown). We further extended the test period to 30 days. Significant deterioration of microcapsule membranes began in the third week when using more concentrated lysozyme $(150 \mu \mathrm{g} / \mathrm{mL})$. As shown in Figure 14(c), fluorescence leakage from the AC microcapsules intensified from 31, 68 to 136 on Days 7, 14 and 21, respectively. The enzyme actions on the GCAC mcirocapsules were much less as evidenced by significant reduced liberation of the enclosed FITC-dextran, with the fluorescence maintained below 40 for the first 2 weeks and reaching a plateau of $\sim 66$ from Day 19 . This indicated the preservation of the GCAC membrane integrity under this offending condition. Exposure to highly concentrated lysozyme $(15 \mathrm{mg} / \mathrm{mL})$ caused considerable leaking of FITCdextran from the AC mcirocapsules, with the intensity escalating from 207, 440 to 582 at the end of the $2 \mathrm{nd}, 3 \mathrm{rd}$ and 4 th week, respectively. In contrast, leaking of the fluorescent marker from the GCAC microcapsules remained insignificant for the first 24 days (intensity <100). Pronounced leaking was detected since Day 28, however the intensity in the challenging media remained less than half as for the AC mcirocapsules (Figure 14(d)). This finding suggested that although deterioration of the GCAC membranes occurred at higher lysozyme concentrations and extended time periods, the covalently cross-linked membrane showed stronger resistance to enzyme degradation compared to the noncrosslinked AC membrane.

\subsection{Resistance of Microcapsules to Simulated Gastrointestinal} Fluids. Oral administration is one of the most preferred routes for therapeutic delivery. However, most macromolecules are susceptible to rapid degradation by the GI impediments [107], for example, the $\mathrm{pH}$ fluctuates from below 2 in the stomach to higher than 7 in the intensity, and the strong proteolytic enzymatic actions exist in the stomach and duodenum [108]. Various encapsulation systems have been proposed in order to target therapeutics absorption from the lower colon and ileum [109-114]. In particular, covalent cross-linking is an effective means to improving chemical and proteolytic resistance to the GI environments $[56,59,115-119]$. In this study, we investigated the resistance 
of the GCAC microcapsules to the simulated GI conditions by sequential incubation with the simulated gastric fluid (SGF, pH 1.2) and the intestinal fluid (SIF, pH 7.5). Results show that the microcapsules remained physically intact in the SGF. After subjected to the SIF, microcapsules with high degree of cross-linking (genipin cross-linking at $20^{\circ} \mathrm{C}$ ) appeared robust and largely retained spherical morphology after 1 week of interaction (Figures 15(a)-15(e)). For those with low cross-linking extent (cross-linked at $4{ }^{\circ} \mathrm{C}$ ), substantial membrane deterioration occurred (Figures 15(f)-15(j)). These indicated that the extent of microcapsule membrane degradation and tolerance to the GI impediments could be regulated to suit different oral applications, for instance, sustained release of drugs to different GI absorption sites, by controlling the degree of cross-linking, which could be achieved by manipulating the chitosan-genipin reaction variables [92] in this membrane and other microcapsule systems $[20,26,27,120]$.

\section{Conclusions}

This paper characterizes the structure and physical properties of the genipin cross-linked alginate-chitosan (GCAC) microcapsules. Results showed that the covalent cross-linked microcapsule membrane possessed strong membrane stability and potent resistance to a number of constraints including mechanical stress, calcium sequestration, enzyme degradation, and GI impediments. Results also demonstrated that the GCAC membrane excluded the infiltration of $70 \mathrm{KD}$ FITC-dextran, while allowing for permeation of bovine serum albumin. These findings suggested that covalent crosslinking by genipin provides considerable improvement in the microcapsule strength and resistance while maintaining the permeability characteristics. Further development of this preparation may permit its use in various biomedical applications.

\section{Acknowledgments}

The authors would like to acknowledge the financial support from Canadian Institutes of Health Research (CIHR). Postgraduate scholarships from Natural Sciences and Engineering Research Council (NSERC) of Canada, Fonds Quebecois de la Recherche sur la Nature et les Technologies (FQRNT), and Greville Smith McGill Major to Chen are appreciated. The authors want to thank L. Mongeon, J Laliberte, H. Vali, R Cohen, TJ Rebello, and B Lawuyi for experimental assistance, and $\mathrm{T}$. Haque for proofreading the manuscript.

\section{References}

[1] T. M. S. Chang, "Semipermeable microcapsules," Science, vol. 146, no. 3643, pp. 524-525, 1964.

[2] T. M. S. Chang, "The role of artificial cells in cell and organ transplantation in regenerative medicine," Panminerva Medica, vol. 47, no. 1, pp. 1-9, 2005.

[3] T. M. S. Chang, "Therapeutic applications of polymeric artificial cells," Nature Reviews Drug Discovery, vol. 4, no. 3, pp. 221-235, 2005.
[4] P. De Vos and P. Marchetti, "Encapsulation of pancreatic islets for transplantation in diabetes: the untouchable islets," Trends in Molecular Medicine, vol. 8, no. 8, pp. 363-366, 2002.

[5] N. O. Dhoot and M. A. Wheatley, "Microencapsulated Liposomes in controlled drug delivery: strategies to modulate drug release and eliminate the burst effect," Journal of Pharmaceutical Sciences, vol. 92, no. 3, pp. 679-689, 2003.

[6] S. Freiberg and X. X. Zhu, "Polymer microspheres for controlled drug release," International Journal of Pharmaceutics, vol. 282, no. 1-2, pp. 1-18, 2004.

[7] G. Orive, R. M. Hernández, A. R. Gascón, et al., "Cell encapsulation: promise and progress," Nature Medicine, vol. 9, no. 1, pp. 104-107, 2003.

[8] H. Tamber, P. Johansen, H. P. Merkle, and B. Gander, "Formulation aspects of biodegradable polymeric microspheres for antigen delivery," Advanced Drug Delivery Reviews, vol. 57, no. 3, pp. 357-376, 2005.

[9] N. K. Varde and D. W. Pack, "Microspheres for controlled release drug delivery," Expert Opinion on Biological Therapy, vol. 4, no. 1, pp. 35-51, 2004.

[10] C. K. Colton, "Engineering challenges in cell-encapsulation technology," Trends in Biotechnology, vol. 14, no. 5, pp. 158$162,1996$.

[11] S. R. Bhatia, S. F. Khattak, and S. C. Roberts, "Polyelectrolytes for cell encapsulation," Current Opinion in Colloid \& Interface Science, vol. 10, no. 1-2, pp. 45-51, 2005.

[12] M. de Groot, T. A. Schuurs, and R. van Schilfgaarde, "Causes of limited survival of microencapsulated pancreatic islet grafts," Journal of Surgical Research, vol. 121, no. 1, pp. 141150, 2004.

[13] A. Fery, F. Dubreuil, and H. Möhwald, "Mechanics of artificial microcapsules," New Journal of Physics, vol. 6, pp. 1-13, 2004.

[14] E. Fournier, C. Passirani, C. N. Montero-Menei, and J. P. Benoit, "Biocompatibility of implantable synthetic polymeric drug carriers: focus on brain biocompatibility," Biomaterials, vol. 24, no. 19, pp. 3311-3331, 2003.

[15] D. Hunkeler, A. Rehor, I. Ceausoglu, et al., "Objectively assessing bioartificial organs," Annals of the New York Academy of Sciences, vol. 944, pp. 456-471, 2001.

[16] A. Prokop, D. Hunkeler, A. C. Powers, R. R. Whitesell, and T. G. Wang, "Water soluble polymers for immunoisolation II: evaluation of multicomponent microencapsulation systems," Advances in Polymer Science, vol. 136, pp. 53-73, 1998.

[17] H. Uludag, P. De Vos, and P. A. Tresco, "Technology of mammalian cell encapsulation," Advanced Drug Delivery Reviews, vol. 42, no. 1-2, pp. 29-64, 2000.

[18] J. Bloch, A. C. Bachoud-Lévi, N. Déglon, et al., "Neuroprotective gene therapy for Huntington's disease, using polymer-encapsulated cells engineered to secrete human ciliary neurotrophic factor: results of a phase I study," Human Gene Therapy, vol. 15, no. 10, pp. 968-975, 2004.

[19] H. Zimmermann, D. Zimmermann, R. Reuss, et al., "Towards a medically approved technology for alginatebased microcapsules allowing long-term immunoisolated transplantation," Journal of Materials Science: Materials in Medicine, vol. 16, no. 6, pp. 491-501, 2005.

[20] A. M. Rokstad, S. Holtan, B. Strand, et al., "Microencapsulation of cells producing therapeutic proteins: optimizing cell growth and secretion," Cell Transplantation, vol. 11, no. 4, pp. 313-324, 2002. 
[21] B. R. S. Hsu, Y. S. Ho, S. H. Fu, Y. Y. Huang, S. C. Chiou, and H. S. Huang, "Membrane compactness affects the integrity and immunoprotection of alginate-poly-L-lysinealginate microcapsules," Transplantation Proceedings, vol. 27, no. 6, pp. 3227-3231, 1995.

[22] B. Thu, P. Bruheim, T. Espevik, O. Smidsrød, P. Soon-Shiong, and G. Skjåk-Bræk, "Alginate polycation microcapsules-II: some functional properties," Biomaterials, vol. 17, no. 11, pp. 1069-1079, 1996.

[23] F. Lim and A. M. Sun, "Microencapsulated islets as bioartifical endocrine pancreas," Science, vol. 210, no. 4472, pp. 908$910,1980$.

[24] P. Soon-Shiong, R. E. Heintz, N. Merideth, et al., "Insulin independence in a type 1 diabetic patient after encapsulated islet transplantation," The Lancet, vol. 343, no. 8903, pp. 950951, 1994.

[25] M. Zhou, D. Chen, Q. Yao, Z. Xia, C. Wang, and H. Zhu, "Microencapsulation of rat islets prolongs xenograft survival in diabetic mice," Chinese Medical Journal, vol. 111, no. 5, pp. 394-397, 1998.

[26] M. Briššová, I. Lacík, A. C. Powers, A. V. Anilkumar, and T. Wang, "Control and measurement of permeability for design of microcapsule cell delivery system," Journal of Biomedical Materials Research, vol. 39, no. 1, pp. 61-70, 1998.

[27] J. M. Van Raamsdonk, R. M. Cornelius, J. L. Brash, and P. L. Chang, "Deterioration of polyamino acid-coated alginate microcapsules in vivo," Journal of Biomaterials Science, Polymer Edition, vol. 13, no. 8, pp. 863-884, 2002.

[28] X. Ma, I. Vacek, and A. Sun, "Generation of alginate-poly1-lysine-alginate (APA) biomicrocapsules: the relationship between the membrane strength and the reaction conditions," Artificial Cells, Blood Substitutes, and Immobilization Biotechnology, vol. 22, no. 1, pp. 43-69, 1994.

[29] M. S. Wang, R. F. Childs, and P. L. Chang, "A novel method to enhance the stability of alginate-poly-L-lysine-alginate microcapsules," Journal of Biomaterials Science, Polymer Edition, vol. 16, no. 1, pp. 91-113, 2005.

[30] O. Gåserød, O. Smidsrød, and G. Skjåk-Bræk, "Microcapsules of alginate-chitosan - I. A quantitative study of the interaction between alginate and chitosan," Biomaterials, vol. 19, no. 20, pp. 1815-1825, 1998.

[31] R. H. Li, "Materials for immunoisolated cell transplantation," Advanced Drug Delivery Reviews, vol. 33, no. 1-2, pp. 87-109, 1998.

[32] M. C. P. Cruz, S. P. Ravagnani, F. M. S. Brogna, et al., "Evaluation of the diffusion coefficient for controlled release of oxytetracycline from alginate/chitosan/poly(ethylene glycol) microbeads in simulated gastrointestinal environments," Biotechnology and Applied Biochemistry, vol. 40, no. 3, pp. 243-253, 2004.

[33] L. R. Moses, K. J. Dileep, and C. P. Sharma, "Beta cyclodextrin-insulin-encapsulated chitosan/alginate matrix: oral delivery system," Journal of Applied Polymer Science, vol. 75, no. 9, pp. 1089-1096, 2000.

[34] T. Metz, M. L. Jones, H. Chen, et al., "A new method for targeted drug delivery using polymeric microcapsules: implications for treatment of Crohn's disease," Cell Biochemistry and Biophysics, vol. 43, no. 1, pp. 77-85, 2005.

[35] P. R. Hari, T. Chandy, and C. P. Sharma, "Chitosan/calcium alginate microcapsules for intestinal delivery of nitrofurantoin," Journal of Microencapsulation, vol. 13, no. 3, pp. 319$329,1996$.
[36] S. Li, X.-T. Wang, X.-B. Zhang, et al., "Studies on alginatechitosan microcapsules and renal arterial embolization in rabbits," Journal of Controlled Release, vol. 84, no. 3, pp. 8798, 2002.

[37] G. Coppi, V. Iannuccelli, E. Leo, M. T. Bernabei, and R. Cameroni, "Protein immobilization in crosslinked alginate microparticles," Journal of Microencapsulation, vol. 19, no. 1, pp. 37-44, 2002.

[38] S.-C. Chen, Y.-C. Wu, F.-L. Mi, Y.-H. Lin, L.-C. Yu, and H.W. Sung, "A novel pH-sensitive hydrogel composed of N,Ocarboxymethyl chitosan and alginate cross-linked by genipin for protein drug delivery," Journal of Controlled Release, vol. 96, no. 2, pp. 285-300, 2004.

[39] D. K. Boadi and R. J. Neufeld, "Encapsulation of tannase for the hydrolysis of tea tannins," Enzyme and Microbial Technology, vol. 28, no. 7-8, pp. 590-595, 2001.

[40] K. W. Lee, J. J. Yoon, J. H. Lee, et al., "Sustained release of vascular endothelial growth factor from calcium-induced alginate hydrogels reinforced by heparin and chitosan," Transplantation Proceedings, vol. 36, no. 8, pp. 2464-2465, 2004.

[41] T. Dastan and K. Turan, "In vitro characterization and delivery of chitosan-DNA microparticles into mammalian cells," Journal of Pharmacy and Pharmaceutical Sciences, vol. 7, no. 2, pp. 205-214, 2004.

[42] D. Quong and R. J. Neufeld, "DNA encapsulation within coguanidine membrane coated alginate beads and protection from extracapsular nuclease," Journal of Microencapsulation, vol. 16, no. 5, pp. 573-585, 1999.

[43] C. Iyer and K. Kailasapathy, "Effect of co-encapsulation of probiotics with prebiotics on increasing the viability of encapsulated bacteria under in vitro acidic and bile salt conditions and in yogurt," Journal of Food Science, vol. 70, no. 1, pp. M18-M23, 2005.

[44] W. Krasaekoopt, B. Bhandari, and H. Deeth, "The influence of coating materials on some properties of alginate beads and survivability of microencapsulated probiotic bacteria," International Dairy Journal, vol. 14, no. 8, pp. 737-743, 2004.

[45] J. S. Lee, D. S. Cha, and H. J. Park, "Survival of freezedried Lactobacillus bulgaricus KFRI 673 in chitosan-coated calcium alginate microparticles," Journal of Agricultural and Food Chemistry, vol. 52, no. 24, pp. 7300-7305, 2004.

[46] Y. Zhou, E. Martins, A. Groboillot, C. P. Champagne, and R. J. Neufeld, "Spectrophotometric quantification of lactic bacteria in alginate and control of cell release with chitosan coating," Journal of Applied Microbiology, vol. 84, no. 3, pp. 342-348, 1998.

[47] D. W. Green, I. Leveque, D. Walsh, et al., "Biomineralized polysaccharide capsules for encapsulation, organization, and delivery of human cell types and growth factors," Advanced Functional Materials, vol. 15, no. 6, pp. 917-923, 2005.

[48] T. Haque, H. Chen, W. Ouyang, et al., "In vitro study of alginate-chitosan microcapsules: an alternative to liver cell transplants for the treatment of liver failure," Biotechnology Letters, vol. 27, no. 5, pp. 317-322, 2005.

[49] A. Zanina, A. Vilesov, and T. Budtova, "Shear-induced solvent release from gel particles: application to drug-delivery systems," International Journal of Pharmaceutics, vol. 242, no. 1-2, pp. 137-146, 2002.

[50] T. Chandy, D. L. Mooradian, and G. H. R. Rao, "Evaluation of modified alginate-chitosan-polyethylene glycol microcapsules for cell encapsulation," Artificial Organs, vol. 23, no. 10, pp. 894-903, 1999. 
[51] D. Maysinger, O. Berezovskaya, and S. Fedoroff, "The hematopoietic cytokine colony stimulating factor 1 is also a growth factor in the CNS: (II) microencapsulated CSF-1 and LM-10 cells as delivery systems," Experimental Neurology, vol. 141, no. 1, pp. 47-56, 1996.

[52] G. Orive, A. Bartkowiak, S. Lisiecki, et al., "Biocompatible oligochitosans as cationic modifiers of alginate/Ca microcapsules," Journal of Biomedical Materials Research, Part B, vol. 74, no. 1, pp. 429-439, 2005.

[53] W. E. Hennink and C. F. van Nostrum, "Novel crosslinking methods to design hydrogels," Advanced Drug Delivery Reviews, vol. 54, no. 1, pp. 13-36, 2002.

[54] L. Richert, F. Boulmedais, P. Lavalle, et al., "Improvement of stability and cell adhesion properties of polyelectrolyte multilayer films by chemical cross-linking," Biomacromolecules, vol. 5, no. 2, pp. 284-294, 2004.

[55] S. G. Kumbar, A. R. Kulkarni, and T. M. Aminabhavi, "Crosslinked chitosan microspheres for encapsulation of diclofenac sodium: effect of crosslinking agent," Journal of Microencapsulation, vol. 19, no. 2, pp. 173-180, 2002.

[56] H. Marchais, G. Cayzeele, J.-Y. Legendre, M. Skiba, and P. Arnaud, "Cross-linking of hard gelatin carbamazepine capsules: effect of dissolution conditions on in vitro drug release," European Journal of Pharmaceutical Sciences, vol. 19, no. 2-3, pp. 129-132, 2003.

[57] Y. Zhang, Y. Guan, and S. Zhou, "Single component chitosan hydrogel microcapsule from a layer-by-layer approach," Biomacromolecules, vol. 6, no. 4, pp. 2365-2369, 2005.

[58] G. M. Cruise, O. D. Hegre, F. V. Lamberti, et al., "In vitro and in vivo performance of porcine islets encapsulated in interfacially photopolymerized poly(ethylene glycol) diacrylate membranes," Cell Transplantation, vol. 8, no. 3, pp. 293 306, 1999.

[59] R. Srivastava, J. Q. Brown, H. Zhu, and M. J. McShane, "Stabilization of glucose oxidase in alginate microspheres with photoreactive diazoresin nanofilm coatings," Biotechnology and Bioengineering, vol. 91, no. 1, pp. 124-131, 2005.

[60] I. Pastoriza-Santos, B. Schöler, and F. Caruso, "Core-shell colloids and hollow polyelectrolyte capsules based on diazoresins," Advanced Funtional Materials, vol. 11, no. 2, pp. 122-128, 2001.

[61] F. Shen, A. A. Li, R. M. Cornelius, et al., "Biological properties of photocrosslinked alginate microcapsules," Journal of Biomedical Materials Research, Part B, vol. 75, no. 2, pp. 425434, 2005.

[62] C. Nishi, N. Nakajima, and Y. Ikada, "In vitro evaluation of cytotoxicity of diepoxy compounds used for biomaterial modification," Journal of Biomedical Materials Research, vol. 29, no. 7, pp. 829-834, 1995.

[63] H.-W. Sung, D.-M. Huang, W.-H. Chang, R.-N. Huang, and J.-C. Hsu, "Evaluation of gelatin hydrogel crosslinked with various crosslinking agents as bioadhesives: in vitro study," Journal of Biomedical Materials Research, vol. 46, no. 4, pp. 520-530, 1999.

[64] W. Friess, "Collagen—biomaterial for drug delivery," European Journal of Pharmaceutics and Biopharmaceutics, vol. 45, no. 2, pp. 113-136, 1998.

[65] H.-W. Sung, I. L. Liang, C.-N. Chen, R.-N. Huang, and H.-F. Liang, "Stability of a biological tissue fixed with a naturally occurring crosslinking agent (genipin)," Journal of Biomedical Materials Research, vol. 55, no. 4, pp. 538-546, 2001.
[66] C. Djerassi, J. D. Gray, and F. A. Kincl, "Naturally occurring oxygen heterocyclics. 9. Isolation and characterization of genipin," Journal of Organic Chemistry, vol. 25, no. 12, pp. 2174-2177, 1960.

[67] Y. Imanishi, N. Maeda, K. Otogawa, et al., "Herb medicine Inchin-ko-to (TJ-135) regulates PDGF-BB-dependent signaling pathways of hepatic stellate cells in primary culture and attenuates development of liver fibrosis induced by thioacetamide administration in rats," Journal of Hepatology, vol. 41, no. 2, pp. 242-250, 2004.

[68] H.-J. Koo, Y. S. Song, H.-J. Kim, et al., "Antiinflammatory effects of genipin, an active principle of gardenia," European Journal of Pharmacology, vol. 495, no. 2-3, pp. 201-208, 2004.

[69] I. Sakaida, M. Tsuchiya, K. Kawaguchi, T. Kimura, S. Terai, and K. Okita, "Herbal medicine Inchin-ko-to (TJ-135) prevents liver fibrosis and enzyme-altered lesions in rat liver cirrhosis induced by a choline-deficient L-amino aciddefined diet," Journal of Hepatology, vol. 38, no. 6, pp. 762769, 2003.

[70] J. Shoda, T. Miura, H. Utsunomiya, et al., "Genipin enhances Mrp2 (Abcc2)-mediated bile formation and organic anion transport in rat liver," Hepatology, vol. 39, no. 1, pp. 167-178, 2004.

[71] M. Yamazaki, K. Chiba, T. Mohri, and H. Hatanaka, "Cyclic GMP-dependent neurite outgrowth by genipin and nerve growth factor in PC12h cells," European Journal of Pharmacology, vol. 488, no. 1-3, pp. 35-43, 2004.

[72] Y.-S. Paik, C.-M. Lee, M.-H. Cho, and T.-R. Hahn, "Physical stability of the blue pigments formed from geniposide of gardenia fruits: effects of ph, temperature, and light," Journal of Agricultural and Food Chemistry, vol. 49, no. 1, pp. 430432, 2001.

[73] F.-L. Mi, H.-W. Sung, and S.-S. Shyu, "Synthesis and characterization of a novel chitosan-based network prepared using naturally occurring crosslinker," Journal of Polymer Science, Part A, vol. 38, no. 15, pp. 2804-2814, 2000.

[74] F.-L. Mi, S.-S. Shyu, and C.-K. Peng, "Characterization of ring-opening polymerization of genipin and $\mathrm{pH}$-dependent cross-linking reactions between chitosan and genipin," Journal of Polymer Science, Part A, vol. 43, no. 10, pp. 1985-2000, 2005.

[75] L. L. H. Huang, H.-W. Sung, C.-C. Tsai, and D.-M. Huang, "Biocompatibility study of a biological tissue fixed with a naturally occurring crosslinking reagent," Journal of Biomedical Materials Research, vol. 42, no. 4, pp. 568-576, 1998.

[76] B.-S. Liu, C.-H. Yao, Y.-S. Chen, and S.-H. Hsu, "In vitro evaluation of degradation and cytotoxicity of a novel composite as a bone substitute," Journal of Biomedical Materials Research, Part A, vol. 67, no. 4, pp. 1163-1169, 2003.

[77] H.-W. Sung, R.-N. Huang, L. L. H. Huang, C.-C. Tsai, and C.T. Chiu, "Feasibility study of a natural crosslinking reagent for biological tissue fixation," Journal of Biomedical Materials Research, vol. 42, no. 4, pp. 560-567, 1998.

[78] H.-W. Sung, R.-N. Huang, L. L. H. Huang, and C.-C. Tsai, "In vitro evaluation of cytotoxicity of a naturally occurring cross-linking reagent for biological tissue fixation," Journal of Biomaterials Science, Polymer Edition, vol. 10, no. 1, pp. 6378, 1999.

[79] M. F. Butler, Y.-F. Ng, and P. D. A. Pudney, "Mechanism and kinetics of the crosslinking reaction between biopolymers containing primary amine groups and genipin," Journal of Polymer Science, Part A, vol. 41, no. 24, pp. 3941-3953, 2003. 
[80] H.-W. Sung, W.-H. Chang, C.-Y. Ma, and M.-H. Lee, "Crosslinking of biological tissues using genipin and/or carbodiimide," Journal of Biomedical Materials Research, vol. 64, no. 3, pp. 427-438, 2003.

[81] J. Jin, M. Song, and D. J. Hourston, "Novel chitosanbased films cross-linked by genipin with improved physical properties," Biomacromolecules, vol. 5, no. 1, pp. 162-168, 2004.

[82] F.-L. Mi, Y.-C. Tan, H.-C. Liang, R.-N. Huang, and H.-W. Sung, "In vitro evaluation of a chitosan membrane crosslinked with genipin," Journal of Biomaterials Science, Polymer Edition, vol. 12, no. 8, pp. 835-850, 2001.

[83] A. Bigi, G. Cojazzi, S. Panzavolta, N. Roveri, and K. Rubini, "Stabilization of gelatin films by crosslinking with genipin," Biomaterials, vol. 23, no. 24, pp. 4827-4832, 2002.

[84] H.-C. Liang, W.-H. Chang, K.-J. Lin, and H.-W. Sung, "Genipin-crosslinked gelatin microspheres as a drug carrier for intramuscular administration: in vitro and in vivo studies," Journal of Biomedical Materials Research, Part A, vol. 65, no. 2, pp. 271-282, 2003.

[85] S. Fujikawa, S. Nakamura, and K. Koga, "Genipin, a new type of protein crosslinking reagent from gardenia fruits," Agricultural and Biological Chemistry, pp. 869-870, 1988.

[86] W.-H. Chang, Y. Chang, Y.-C. Chen, and H.-W. Sung, "Hemoglobin polymerized with a naturally occurring crosslinking agent as a blood substitute: in vitro and in vivo studies," Artificial Cells, Blood Substitutes, and Immobilization Biotechnology, vol. 32, no. 2, pp. 243-262, 2004.

[87] Y.-S. Chen, J.-Y. Chang, C.-Y. Cheng, F.-J. Tsai, C.-H. Yao, and B.-S. Liu, "An in vivo evaluation of a biodegradable genipincross-linked gelatin peripheral nerve guide conduit material," Biomaterials, vol. 26, no. 18, pp. 3911-3918, 2005.

[88] Y. Chang, H.-C. Liang, H.-J. Wei, C.-P. Chu, and H.-W. Sung, "Tissue regeneration patterns in acellular bovine pericardia implanted in a canine model as a vascular patch," Journal of Biomedical Materials Research, Part A, vol. 69, no. 2, pp. 323333, 2004.

[89] H.-C. Liang, Y. Chang, C.-K. Hsu, M.-H. Lee, and H.-W. Sung, "Effects of crosslinking degree of an acellular biological tissue on its tissue regeneration pattern," Biomaterials, vol. 25, no. 17, pp. 3541-3552, 2004.

[90] H. Chen, W. Ouyang, M. Jones, et al., "Preparation and characterization of novel polymeric microcapsules for live cell encapsulation and therapy," Cell Biochemistry and Biophysics, vol. 47, no. 1, pp. 159-167, 2007.

[91] C.-S. Ko and I.-M. Chu, "Immobilized cells biocatalyst for the production of S-acetylthio-2-methyl propionic acid," Enzyme and Microbial Technology, vol. 35, no. 6-7, pp. 619623, 2004.

[92] H. Chen, W. Ouyang, B. Lawuyi, and S. Prakash, "Genipin cross-linked alginate-chitosan microcapsules: membrane characterization and optimization of cross-linking reaction," Biomacromolecules, vol. 7, no. 7, pp. 2091-2098, 2006.

[93] J. M. Van Raamsdonk and P. L. Chang, "Osmotic pressure test: a simple, quantitative method to assess the mechanical stability of alginate microcapsules," Journal of Biomedical Materials Research, vol. 54, no. 2, pp. 264-271, 2001.

[94] A. Martinsen, G. Skjåk-Bræk, and O. Smidsrød, "Alginate as immobilization material-I: correlation between chemical and physical properties of alginate gel beads," Biotechnology and Bioengineering, vol. 33, no. 1, pp. 79-89, 1989.
[95] O. Smidsrød and G. Skjåk-Bræk, "Alginate as immobilization matrix for cells," Trends in Biotechnology, vol. 8, no. 3, pp. 71-78, 1990.

[96] J. Dusseault, F. A. Leblond, R. Robitaille, et al., "Microencapsulation of living cells in semi-permeable membranes with covalently cross-linked layers," Biomaterials, vol. 26, no. 13, pp. 1515-1522, 2005.

[97] M. Darrabie, B. K. Freeman, W. F. Kendall Jr., H. A. Hobbs, and E. C. Opara, "Durability of sodium sulfate-treated polylysine-alginate microcapsules," Journal of Biomedical Materials Research, vol. 54, no. 3, pp. 396-399, 2001.

[98] C. J. D. Ross and P. L. Chang, "Development of small alginate microcapsules for recombinant gene product delivery to the rodent brain," Journal of Biomaterials Science, Polymer Edition, vol. 13, no. 8, pp. 953-962, 2002.

[99] M. D. Darrabie, W. F. Kendall Jr., and E. C. Opara, "Characteristics of poly-L-ornithine-coated alginate microcapsules," Biomaterials, vol. 26, no. 34, pp. 6846-6852, 2005.

[100] M. Brissova, M. Petro, I. Lacík, A. C. Powers, and T. Wang, "Evaluation of microcapsule permeability via inverse size exclusion chromatography," Analytical Biochemistry, vol. 242, no. 1, pp. 104-111, 1996.

[101] W. W. Stewart and H. E. Swaisgood, "Characterization of calcium alginate pore diameter by size-exclusion chromatography using protein standards," Enzyme and Microbial Technology, vol. 15, no. 11, pp. 922-927, 1993.

[102] S. Rosiński, D. Lewińska, M. Wójcik, G. Orive, J. L. Pedraz, and A. Weryński, "Mass transfer characteristics of polylysine, poly-ornithine and poly-methylene-co-guanidine membrane coated alginate microcapsules," Journal of Membrane Science, vol. 254, no. 1-2, pp. 249-257, 2005.

[103] D. E. Awrey, M. Tse, G. Hortelano, and P. L. Chang, "Permeability of alginate microcapsules to secretory recombinant gene products," Biotechnology and Bioengineering, vol. 52, no. 4, pp. 472-484, 1996.

[104] M. Peirone, C. J. D. Ross, G. Hortelano, J. L. Brash, and P. L. Chang, "Encapsulation of various recombinant mammalian cell types in different alginate microcapsules," Journal of Biomedical Materials Research, vol. 42, no. 4, pp. 587-596, 1998.

[105] N. Okada, H. Miyamoto, T. Yoshioka, et al., "Immunological studies of SK2 hybridoma cells microencapsulated with alginate-poly(L)lysine-alginate (APA) membrane following allogeneic transplantation," Biochemical and Biophysical Research Communications, vol. 230, no. 3, pp. 524-527, 1997.

[106] M. F. A. Goosen, G. A. King, C. A. McKnight, and N. Marcotte, "Animal cell culture engineering using alginate polycation microcapsules of controlled membrane molecular weight cut-off," Journal of Membrane Science, vol. 41, pp. 323-343, 1989.

[107] M. Goldberg and I. Gomez-Orellana, "Challenges for the oral delivery of macromolecules," Nature Reviews Drug Discovery, vol. 2, no. 4, pp. 289-295, 2003.

[108] S. Salminen and M. Gueimonde, "Human studies on probiotics: what is scientifically proven," Journal of Food Science, vol. 69, no. 5, pp. M137-M140, 2004.

[109] V. Chandramouli, K. Kailasapathy, P. Peiris, and M. Jones, "An improved method of microencapsulation and its evaluation to protect Lactobacillus spp. in simulated gastric conditions," Journal of Microbiological Methods, vol. 56, no. 1, pp. 27-35, 2004. 
[110] J. Kovacs-Nolan and Y. Mine, "Microencapsulation for the gastric passage and controlled intestinal release of immunoglobulin Y," Journal of Immunological Methods, vol. 296, no. 1-2, pp. 199-209, 2005.

[111] A. Lamprecht, H. Yamamoto, H. Takeuchi, and Y. Kawashima, "Observations in simultaneous microencapsulation of 5-fluorouracil and leucovorin for combined pH-dependent release," European Journal of Pharmaceutics and Biopharmaceutics, vol. 59, no. 2, pp. 367-371, 2005.

[112] Y.-H. Lin, H.-F. Liang, C.-K. Chung, M.-C. Chen, and H.-W. Sung, "Physically crosslinked alginate/N,O-carboxymethyl chitosan hydrogels with calcium for oral delivery of protein drugs," Biomaterials, vol. 26, no. 14, pp. 2105-2113, 2005.

[113] V. Pillay and R. Fassihi, "In vitro release modulation from crosslinked pellets for site-specific drug delivery to the gastrointestinal tract-II: physicochemical characterization of calcium-alginate, calcium-pectinate and calcium-alginatepectinate pellets," Journal of Controlled Release, vol. 59, no. 2, pp. 243-256, 1999.

[114] I. El-Gibaly, "Development and in vitro evaluation of novel floating chitosan microcapsules for oral use: comparison with non-floating chitosan microspheres," International Journal of Pharmaceutics, vol. 249, no. 1-2, pp. 7-21, 2002.

[115] J. Brown, N. Madit, E. T. Cole, I. R. Wilding, and D. Cadé, "The effect of cross-linking on the in vivo disintegration of hard gelatin capsules," Pharmaceutical Research, vol. 15, no. 7, pp. 1026-1030, 1998.

[116] K. G. H. Desai and H. J. Park, "Encapsulation of vitamin C in tripolyphosphate cross-linked chitosan microspheres by spray drying," Journal of Microencapsulation, vol. 22, no. 2, pp. 179-192, 2005.

[117] M. C. Meyer, A. B. Straughn, R. M. Mhatre, et al., "The effect of gelatin cross-linking on the bioequivalence of hard and soft gelatin acetaminophen capsules," Pharmaceutical Research, vol. 17, no. 8, pp. 962-966, 2000.

[118] M.-K. Park, S. Deng, and R. C. Advincula, "Sustained release control via photo-cross-linking of polyelectrolyte layer-bylayer hollow capsules," Langmuir, vol. 21, no. 12, pp. 52725277, 2005.

[119] E. Taqieddin and M. Amiji, "Enzyme immobilization in novel alginate-chitosan core-shell microcapsules," Biomaterials, vol. 25, no. 10, pp. 1937-1945, 2004.

[120] H. Chen, W. Ouyang, M. Jones, T. Haque, B. Lawuyi, and S. Prakash, "In-vitro analysis of APA microcapsules for oral delivery of live bacterial cells," Journal of Microencapsulation, vol. 22, no. 5, pp. 539-547, 2005. 

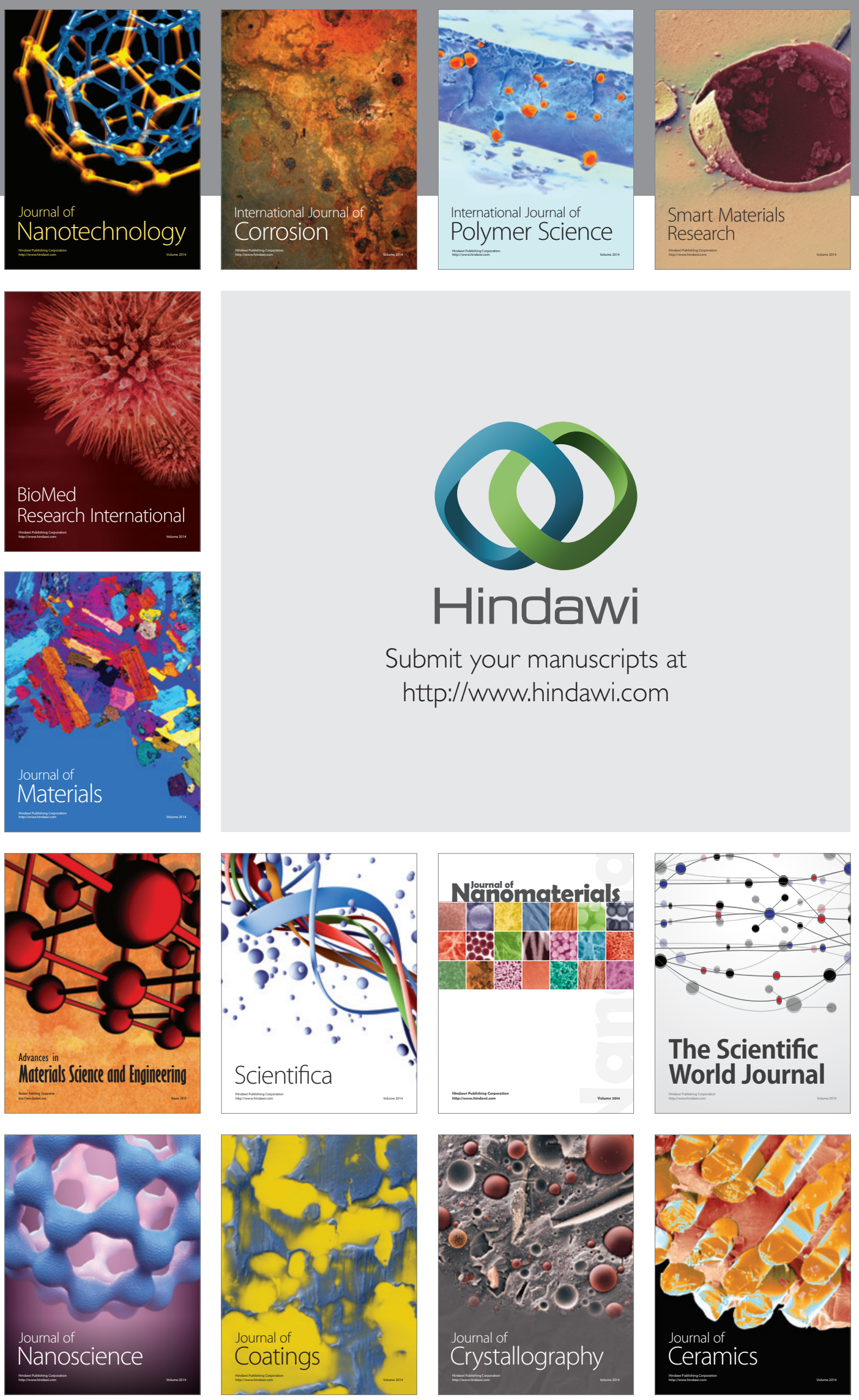

The Scientific World Journal

Submit your manuscripts at

http://www.hindawi.com

\section{World Journal}

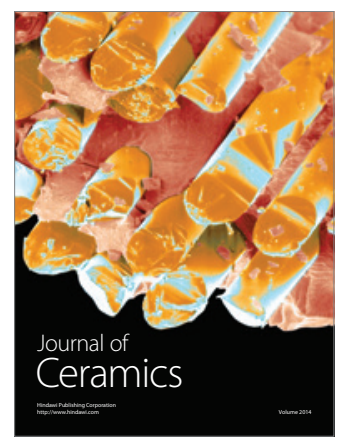

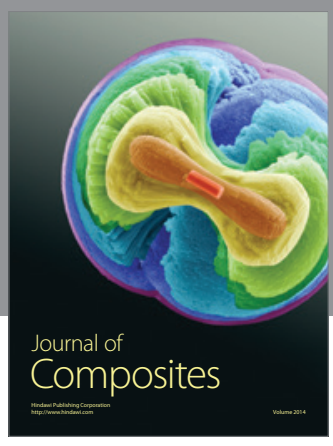
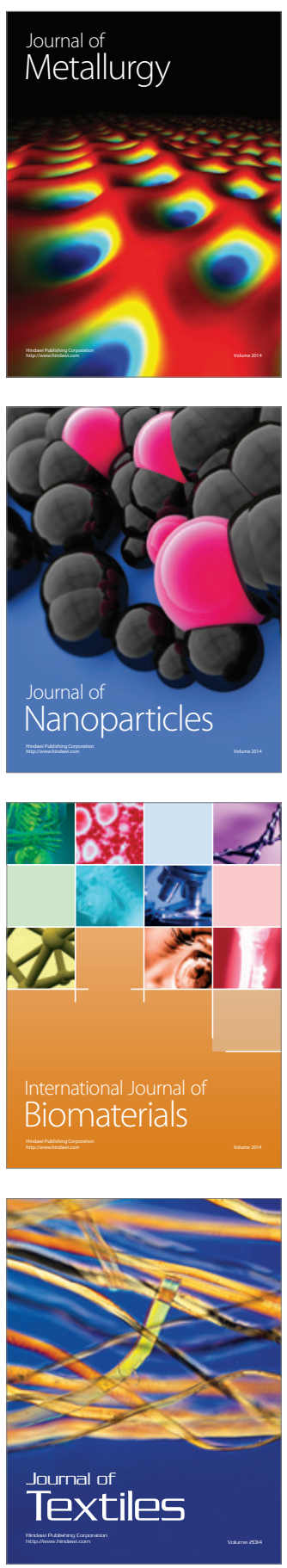